\title{
INDICADORES DE INFLACIÓN SUBYACENTE PARA COSTA RICA BASADOS EN EXCLUSIÓN Y EN REPONDERACIÓN
}

\author{
Adolfo Rodríguez Vargas ${ }^{1}$ \\ Melissa Vega Monge ${ }^{2}$
}

Recibido: 20/01/2014

Aprobado: 19/05/2014

\begin{abstract}
RESUMEN
En este trabajo se evalúa el desempeño de nuevos indicadores de inflación subyacente para Costa Rica construidos mediante la metodología de exclusión y la de reponderación de artículos de la canasta del índice oficial. Se construyen indicadores de exclusión basados en la eliminación de categorías fijas del Índice de Precios al Consumidor (IPC), así como varias versiones alternativas según la metodología de exclusión de productos con base en una medida de su volatilidad, utilizando datos a diciembre del 2012. Por otra parte, se construyen dos tipos de indicadores reponderados: por volatilidad y por persistencia. Para reponderar por persistencia se utiliza un estimador basado en el espectro de la serie de cambios en precio, tres indicadores basados en una metodología de coeficientes autorregresivos, un indicador de reversión a la media y otro basado en la correlación que existe entre las series de precio de cada artículo de la canasta con las variaciones de la inflación futura. Se evalúa el insesgamiento, el ajuste a la tendencia de inflación, la capacidad predictiva de la inflación oficial, así como las propiedades de largo plazo de cada indicador. Con base en los resultados de esta evaluación se recomienda dar seguimiento a uno de los indicadores de reponderación por volatilidad y a uno de los indicadores de reponderación por persistencia.
\end{abstract}

PALABRAS CLAVE: INFLACIÓN SUBYACENTE, VOLATILIDAD, PERSISTENCIA, INSESGAMIENTO, PRONÓSTICOS.

\begin{abstract}
We evaluate the performance of new core inflation indicators for Costa Rica, computed through the exclusion or reweighting of the items in the CPI basket. We construct exclusion indicators based on the elimination of fixed categories of the CPI, as well as alternative versions of an indicator calculated by excluding articles according to their volatility, using data updated to December 2012. We also construct two types of reweighted indicators: one type using volatility measures and the other using persistence measures. Persistence reweighting is based either on the estimated spectrum of the series of price
\end{abstract}


changes, three indicators based in an autoregressive coefficients methodology, a meanreversion indictor, or an indicator based on the correlation of each series of price changes with variations in future inflation. For each indicator, we evaluate unbiasedness, fit to trend inflation, predictive ability and long-run behaviour. From the results of this evaluation, we recommend monitoring one of the volatility-weighted indicators and one of the persistence-weighted indicators.

KEY WORDS: CORE INFLATION, VOLATILITY, PERSISTENCE, UNBIASEDNESS, FORECASTS.

\section{INTRODUCCIÓN}

Para la formulación de política monetaria un banco central requiere, en palabras de Blinder (1997), "distinguir la señal del ruido" en la información disponible sobre inflación. Con ese objetivo, las medidas de inflación subyacente buscan identificar los movimientos de los precios que se deben a presiones monetarias (la "señal"), de forma que se atenúe la influencia de variaciones pasajeras (el "ruido") asociadas, por ejemplo, con factores climáticos, estacionales o institucionales.

Con ese objetivo, los bancos centrales han adoptado el cálculo de medidas de inflación que aíslen de forma efectiva el componente transitorio del permanente en las variaciones de precios, capturando la noción de una inflación asociada únicamente a presiones monetarias. Estas medidas son conocidas como de inflación subyacente ${ }^{3}$. Se han desarrollado diferentes enfoques y metodologías para la construcción de este tipo de indicadores que abarcan desde métodos simples, como la exclusión de grupos o productos específicos, hasta metodologías más sofisticadas como el análisis de las series en el dominio de la frecuencia. Para el caso de Costa Rica, actualmente se calculan dos indicadores de inflación subyacente que publica el Banco Central de Costa Rica (BCCR): el Índice de Inflación Subyacente (ISI) y la Inflación de Media Truncada (IMT).

Saborío, Solano y Solera (2002) calculan el Índice de Inflación Subyacente (ISI), que excluye un $34,04 \%$ del peso total ${ }^{4}$ del Índice de Precios al Consumidor (IPC) siguiendo un criterio de exclusión por variabilidad relativa que se evaluó por medio del ajuste con la tendencia inflacionaria. Se adoptó en el 2002 sustituyendo al Índice de Núcleo Inflacionario (INI) que excluía el 48\% de la canasta de consumo y que presentaba algunas limitaciones de carácter metodológico.

El IMT para Costa Rica se construyó a partir del trabajo de Esquivel, Rodríguez y Vásquez (2011), que consistió en el cálculo de medias truncadas centradas alrededor de un estimador del percentil poblacional de la media de los cambios en precios de los artículos del IPC. Los autores estiman que la media de los cambios de precio para los datos mensuales se ubica en el percentil 60, revelando que la distribución presenta una asimetría "crónica" hacia la derecha. Mediante pruebas de insesgamiento, capacidad de pronóstico y ajuste con la tendencia encuentran los truncamientos óptimos: $30 \%$ a la izquierda y $10 \%$ a la derecha de la distribución. Asimismo se demostró que esta medida presenta un mejor ajuste con la tendencia inflacionaria y menor variabilidad que el ISI.

Rodríguez (2011) realiza un análisis en el dominio de la frecuencia para 22 indicadores de precios en Costa Rica, incluyendo el ISI $y$ dos versiones de medias truncadas, $y$ encuentra conveniente actualizar la canasta de productos empleada para el cálculo del ISI, así como contrastar las propiedades del indicador resultante con las de medidas alternativas de inflación subyacente para Costa Rica.

3 El concepto fue introducido por Gordon (1975) quien inicialmente lo definió como el crecimiento en el nivel agregado de precios, excluyendo alimentos y energía.

4

Porcentaje actualizado según la revisión del 2006.

Ciencias Económicas 32-No. 1: 2014 / 117-162 / ISSN: 0252-9521 
Además de actualizar la canasta del ISI, se calcula indicadores de inflación subyacente mediante dos enfoques: la metodología de exclusión, que es la más común entre los bancos centrales por su facilidad de interpretación y comunicación al público, y la metodología de reponderación, ya puesta en práctica por algunos bancos centrales como el Banco de Canadá, pero que aún no se ha aplicado para el caso de Costa Rica.

Se calculan 4 indicadores de exclusión, que se basan en la eliminación de categorías fijas y previamente definidas del IPC, y 11 nuevos indicadores de inflación subyacente que siguen la metodología de exclusión de productos volátiles calculadas a partir de la revisión y actualización de los datos de precios con información a diciembre del 2012. Además, se calculan nuevos indicadores basados en dos tipos de reponderación: por volatilidad y por persistencia ${ }^{5}$. Asimismo, se incluyen el ISI actual (revisión 2006) y el IMT, como referencias para la evaluación de los indicadores propuestos.

Se realizan pruebas de insesgamiento, de ajuste a tendencia de inflación, de predicción de la dirección de cambios con respecto a la inflación oficial, de capacidad predictiva, y pruebas para evaluar propiedades de largo plazo basadas en VAR estructurales (SVAR).

Este documento se estructura de la siguiente forma: en la sección 2 se presenta una descripción de los datos y metodologías, en la sección 3 se describen los indicadores calculados y se contrastan los enfoques empleados, en la sección 4 se presenta la evaluación de los indicadores y finalmente, en la sección 5 se presenta las conclusiones y las recomendaciones sobre la eventual aplicación de los indicadores.

\section{DATOS Y METODOLOGÍA}

Para reducir la influencia de variaciones idiosincráticas de precios en la medida de inflación se suele aplicar métodos de exclusión, de reponderación o de influencia limitada. Este trabajo se concentra en los primeros dos, cuyas particularidades de cálculo y datos requeridos se explican en esta sección.

\section{Datos}

Todos los indicadores se construyen usando datos para el período julio 2006 - diciembre 2012, para los 292 artículos que componen la canasta del Índice de Precios al Consumidor (IPC), con base julio 2006, calculado mensualmente por el Instituto Nacional de Estadística y Censos (INEC) ${ }^{6}$. La canasta del IPC se subdivide en 12 grupos, cuyo peso y número de artículos se presentan en el cuadro 1. La lista completa de artículos se ubica en el anexo.

5 Por lo general, la persistencia inflacionaria se define como la velocidad con la que la inflación regresa a su valor de equilibrio de largo plazo después de una perturbación. Algunos estudios que adoptan esta definición son Willis (2003); Batini y Nelson (2002); Andrews y Chen (1994); D’Amato, Garegnani, y Sotes (2008), y Chaverri y Torres (2010) para el caso de Costa Rica.

6 Para una exposición completa de la metodología de cálculo del IPC, véase INEC (2006), disponible en www.inec.go.cr. 


\section{CUADRO 1 \\ COMPOSICIÓN DE LA CANASTA DEL IPC}

\begin{tabular}{lcc}
\hline Grupo & Peso & Artículos \\
\hline Alimentos y bebidas no alcohólicas & $18,61 \%$ & 99 \\
Bebidas alcohólicas y cigarrillos & $0,69 \%$ & 4 \\
Comidas y bebidas fuera del hogar & $8,61 \%$ & 11 \\
Prendas de vestir y calzado & $5,86 \%$ & 25 \\
Alquiler y servicios de la vivienda & $10,64 \%$ & 11 \\
Artículos para la vivienda y servicio doméstico & $8,65 \%$ & 36 \\
Salud & $4,81 \%$ & 17 \\
Transporte & $18,19 \%$ & 20 \\
Comunicaciones & $4,45 \%$ & 4 \\
Entretenimiento y cultura & $7,25 \%$ & 25 \\
Educación & $5,89 \%$ & 15 \\
Bienes y servicios diversos & $6,35 \%$ & 25 \\
\hline Total & $100,00 \%$ & 292 \\
\hline
\end{tabular}

Fuente: INEC.

El nivel del IPC en el mes $t, I P C$, se define como

$$
I P C_{t}=\frac{\sum_{i=1}^{292} I_{t}^{i} w_{i}}{w_{G}}
$$

donde $l_{t}^{i}$ es el nivel del índice para el artículo $i$ en el mes $t, w_{i}$ es su peso en la canasta y $w_{G}$ es la suma de todos los pesos, que es igual a 1 . El nivel para el índice general también se puede expresar como

$$
I P C_{t}=\sum_{i=1}^{292} C_{t}^{i}
$$

donde el costo $C_{t}^{i}$ de cada artículo es el valor de su peso $w_{i}$ actualizado usando las variaciones mes contra mes de $l_{t}^{i}$. En los cálculos se usaron las series para $C_{t}^{i}$ o las variaciones mes contra mes de $l_{t}^{i}$, dependiendo de los requerimientos de cada método.

Se aplicó la prueba UDMax (Double Maximum Test) propuesta por Bai-Perron (2003), que considera una hipótesis nula de ausencia de quiebres estructurales contra la hipótesis alternativa que señala la existencia de un número desconocido de quiebres. A un nivel de significancia del 5\%, los resultados permiten rechazar la hipótesis nula de ausencia de quiebres para 91 de las 292 series que se evaluaron. Dado este resultado, se efectuó una prueba secuencial, que evaluó la presencia de $l+1$ contra $l$ quiebres. Los resultados apuntan a la presencia de un solo quiebre estructural contra $l$ la existencia de 2 quiebres estructurales ${ }^{7}$. Este resultado deberá tomarse en cuenta a la hora de realizar algunas de las estimaciones necesarias para calcular los indicadores.

$7 \quad$ Los datos de las pruebas no se presentan por razones de espacio, pero están disponibles mediante solicitud a los autores. 


\section{Medidas de exclusión}

Este tipo de indicadores de inflación subyacente se calcula omitiendo los datos de un subconjunto de la canasta del IPC que incluye los artículos cuyos precios son volátiles:

$$
I_{t}^{e x c l}=\frac{\sum_{i \notin B} I_{t}{ }^{i} w_{i}}{\sum_{i \notin B} w_{i}}
$$

La composición de este subconjunto $B$ no cambia de período a período. Se considera que los movimientos en los precios de estos artículos no reflejan movimientos asociados con presiones monetarias, sino que se asociarían mayoritariamente con la situación vigente de ese mercado particular (estacionalidad, choques asociados a factores climáticos).

La composición del conjunto excluido $B$ se determina mediante dos métodos. El primero es excluir categorías enteras de productos, o bien productos específicos cuyos cambios de precio se consideran especialmente volátiles, usualmente alimentos y combustibles.

El segundo método implica excluir un conjunto de artículos de acuerdo con criterios estadísticos. Se ordena los artículos del IPC de forma descendente de acuerdo con la variancia histórica de sus variaciones de precio, $y$ se calcula índices de precios que progresivamente excluyan un subconjunto mayor de artículos, empezando por el más volátil. El porcentaje de exclusión óptimo usualmente se elige con base en el ajuste del índice de precios resultante a una medida de tendencia de la inflación. Con este método se determinó la composición de la canasta de productos excluidos para calcular el Índice de Inflación Subyacente (ISI), que actualmente excluye un total de 55 artículos, correspondientes a 34,04\% del peso de la canasta del IPC ${ }^{8}$.

Es oportuno recordar la diferencia entre indicadores de exclusión e indicadores de influencia limitada. Estos últimos buscan evitar que la medida de inflación se vea influida por distribuciones muestrales atípicas de variaciones de precios. Para ello, se elimina del cálculo las variaciones más altas y las más bajas ocurridas en los precios de los artículos de la canasta en ese período. A diferencia de un indicador de exclusión, el tamaño y la conformación del grupo de artículos no incluidos en el cálculo puede cambiar, de manera que artículos excluidos de la canasta de cálculo en un período podrían estar incluidos en otro. El Banco Central de Costa Rica (BCCR) publica un indicador de este tipo, la Inflación de Media Truncada (IMT) utilizando un truncamiento asimétrico centrado en el percentil de la media. Los detalles de su cálculo pueden verse en Esquivel, Rodríguez y Vázquez (2011).

El cuadro 2 lista los indicadores de exclusión que se calculan y evalúan en este trabajo. Los primeros cuatro son calculados por el BCCR para su uso interno, mediante el primero de los métodos de exclusión referidos. También se calculan varios indicadores calculados mediante la metodología de exclusión por volatilidad (al igual que el ISI), cada uno con un porcentaje de exclusión distinto, de entre los cuales se identificará los que tengan un mejor desempeño que el ISI. El ordenamiento por volatilidad se realizó a partir de la estimación de las variancias de las series de variaciones mensuales para cada artículo. 
CUADRO 2

INDICADORES DE EXCLUSIÓN SOMETIDOS A EVALUACIÓN

\begin{tabular}{ll}
\hline Indicador & Canasta utilizada para cálculo \\
\hline IPCX & Canasta IPC menos combustible para vehículos, frutas, $y$ hortalizas, leguminosasy tubérculos \\
IPCX1 & Canasta IPCX menos carnes, pescado fresco y precios regulados \\
IPCX2 & Canasta IPC menos alimentos, combustibles y regulados \\
IPCX3 & Canasta IPC menos alimentos y combustibles para vehículo \\
ISI_j & Canasta IPC menos subconjunto de j artículos con los precios más volátiles \\
\hline
\end{tabular}

Fuente: elaboración propia.

Debe destacarse que la elección del porcentaje de exclusión óptimo para un nuevo indicador de inflación subyacente se realizará considerando los resultados de las pruebas de insesgamiento, de capacidad de pronóstico y de propiedades de largo plazo, lo que implica una mejora metodológica con respecto a la última actualización de la canasta del indicador.

\section{Medidas de reponderación}

En las medidas de exclusión, al asignarse un peso de cero a los artículos más volátiles, se está suponiendo que todos los movimientos en esos precios son ruido o bien choques aislados y pasajeros. Sin embargo, podría ser deseable no excluir totalmente la información de estos cambios, por cuanto algunos de ellos podría deberse a presiones inflacionarias.

A diferencia de las medidas de exclusión o las de influencia limitada, en los indicadores de reponderación se incluye información de la totalidad de los artículos de la canasta del IPC, aunque con una ponderación distinta a la original. Esta reponderación de los pesos originales se realiza con el objetivo de reducir la influencia de artículos cuyas variaciones de precios han mostrado ser volátiles o en general incompatibles con el concepto de inflación como variación sostenida de precios asociada con excesos monetarios. Un indicador de reponderación se calcula de la siguiente manera

$$
I_{t}^{\text {rep }}=\frac{\sum_{i=1}^{N} I_{t}^{i} g_{i}}{\sum_{i=1}^{N} g_{i}} \text { con } g_{i}=w_{i} r_{i},
$$

donde $r_{i}$ es un indicador utilizado para la reponderación de los pesos originales $w_{i}$. En la práctica, este indicador se suele basar en estimaciones de volatilidad o de persistencia para la serie de variaciones de precio del artículo $i$.

\section{Reponderación por volatilidad}

La idea este método es que la ponderación de los artículos de la canasta vaya en relación inversa a la volatilidad de sus precios, reduciendo así el efecto sobre el índice agregado de artículos cuyos precios suelen ser más influidos por condiciones pasajeras. Diewert (1995) propone una medida "neo-Edgeworthiana" de inflación que se construye como un promedio ponderado de las variaciones de los artículos individuales, cuyos pesos vienen dados por el inverso de las variancias de las series de variaciones individuales 


$$
\pi_{t}=\frac{\sum_{i=1}^{N} \pi_{t}^{i} r_{i}}{\sum_{i=1}^{N} r_{i}} \text { con } r_{i}=1 / \hat{\sigma}_{i}^{2}
$$

Nótese que en este caso no se considera el peso de cada artículo dentro de una canasta de consumo, como la del IPC, sino que el recíproco de la variancia es la única ponderación. Si además de considerar la volatilidad en el precio del artículo se desea incorporar en el cálculo del indicador la importancia de cada artículo en el gasto $\left(w_{i}\right)$, se requiere aplicar el método de doble ponderación. En este caso, el indicador se calcularía como

$$
\pi_{t}=\frac{\sum_{i=1}^{N} \pi_{t}^{i} g_{i}}{\sum_{i=1}^{N} g_{i}} \text { con } g_{i}=w_{i} r_{i}, r_{i}=1 / v_{i},
$$

donde $v_{i}$ es un indicador de volatilidad. Un ejemplo de este tipo de indicador es el CPIW, calculado por el Banco de Canadá, en el que $v_{i}$ es la desviación estándar de la variación de precios relativos para el artículo $i^{9}$.

La reponderación por volatilidad implica un elemento de arbitrariedad en la elección del indicador y del período usado. En particular, un período fijo podría afectar la confiabilidad del indicador si la variabilidad de los artículos muestra cambios posteriores. Por eso, en este estudio se realiza la reponderación por volatilidad considerando la información actualizada al momento del cálculo. En dos de los indicadores, utilizamos como medida de volatilidad la desviación estándar de las variaciones de precio del artículo $i$ con toda la información vigente a cada fecha $t$. En los restantes, utilizamos variancias calculadas mediante ventanas móviles de 24 o 36 meses. Los indicadores calculados se describen en el cuadro 3.

CUADRO 3

\begin{tabular}{|c|c|c|c|}
\hline Indicador & Tipo de ponderación & Ponderador de volatilidad & Período de cálculo \\
\hline R_1_inversa_volat & Solo por volatilidad & \multirow{2}{*}{$\begin{array}{l}\text { Inverso de la desviación } \\
\text { estándar de serie de variación } \\
\text { de precios }\end{array}$} & \multirow{2}{*}{$\begin{array}{l}\text { 2006:07 - último mes } \\
\text { disponible }\end{array}$} \\
\hline R_2_inversa_volat & Por volatilidad y peso en consumo. & & \\
\hline R_1_var_movil24 & Solo por volatilidad & \multirow{4}{*}{$\begin{array}{l}\text { Inverso de la variancia de serie } \\
\text { de variación de precios }\end{array}$} & \multirow{2}{*}{$\begin{array}{l}\text { Ventana móvil } \\
\text { con las últimas } 24 \\
\text { observaciones }\end{array}$} \\
\hline R_2_var_movil24 & Por volatilidad y peso en consumo. & & \\
\hline R_1_var_movil36 & Solo por volatilidad & & \multirow{2}{*}{$\begin{array}{l}\text { Ventana móvil } \\
\text { con las últimas } 36 \\
\text { observaciones }\end{array}$} \\
\hline R_2_var_movil36 & Por volatilidad y peso en consumo. & & \\
\hline
\end{tabular}

INDICADORES DE REPONDERACIÓN POR VOLATILIDAD SOMETIDOS A EVALUACIÓN

Fuente: elaboración propia.

$9 \quad$ Ver Hogan, Johnson y Laflèche (2001). 


\section{Reponderación basada en persistencia de las series}

El enfoque basado en persistencia se encuentra intrínsecamente ligado al objetivo de construir una medida que permita aislar de forma efectiva el componente menos duradero de la inflación. En este sentido, Blinder (1997) define el componente duradero como el que es útil para pronosticar la inflación de corto y mediano plazo, o en su defecto, el horizonte que se considere relevante en términos de política monetaria. Este concepto pone de manifiesto uno de los grandes retos que enfrentan los bancos centrales a la hora distinguir el componente de la inflación que representa fluctuaciones transitorias y la parte que proporciona indicios adelantados de cambios mucho más permanentes en la tendencia, los cuales pueden afectar el objetivo primordial de estabilidad de precios.

Blinder (1997) aclara que es fundamental entender que el interés de los bancos centrales es aislar el componente duradero por su valor para pronosticar la inflación de corto y mediano plazo. Así, recomienda ajustar el peso de cada bien o servicio con base en su capacidad predictiva y detalla que se debería hacer una nueva ponderación de la canasta considerando la persistencia de cada producto y su covarianza con la inflación oficial de referencia.

Uno de los primeros intentos para operacionalizar este concepto fue propuesto por Cutler (2001) para Reino Unido. La autora propone una metodología de reasignación de pesos, para la canasta de consumo que conforma el RPIX ${ }^{10}$, utilizando la persistencia que los componentes mostraron en el pasado. Para esto, recurrió a un modelo autorregresivo de orden 1, para estimar la ponderación por medio de los coeficientes $\beta_{i}$ :

$$
\Delta p_{i, t}=\alpha_{i}+\beta_{i} \Delta p_{i, t-12}
$$

Si el coeficiente $\beta_{i}$ es negativo, se le asigna un valor de cero, ya que un valor negativo se interpretaría como señal de una persistencia baja. Posteriormente, los demás coeficientes son reescalados para sumar uno. El modelo se estima de forma recursiva para actualizar los coeficientes anualmente. Se encuentra que este índice presenta buenas propiedades predictivas para horizontes de 6 y 12 meses, horizontes relevantes de política monetaria. Asimismo, el índice obtuvo mejores resultados que las medidas de exclusión por grupos.

Dando seguimiento a las ideas de Cutler y Blinder, Bilke y Stracca (2008) formulan una nueva propuesta planteando que los indicadores de persistencia son útiles en la medida en que se encuentren relacionados con las decisiones de política monetaria, y relacionan el concepto de persistencia con la velocidad a la que se converge al equilibrio luego de un choque. De esta forma, entre más tiempo se tarde en retornar al equilibrio, más persistente es el componente que se está evaluando.

Una observación que se considera relevante en el análisis efectuado por Bilke y Stracca (2008), relacionada con las sugerencias planteadas por Blinder, es que

"En un ambiente de estabilidad de precios donde el banco central reacciona agresivamente y de forma oportuna a las presiones inflacionarias, es altamente improbable encontrar un indicador de inflación subyacente que sistemáticamente esté correlacionado con la inflación futura". ( $p .5)$

Bilke y Stracca (2008) desarrollaron tres medidas de persistencia para la zona del euro que fueron evaluadas, entre otras propiedades, por su capacidad de correlacionarse con las decisiones 10 Es una medida de inflación similar al RPI (Retail Prices Index) pero excluyendo pagos de intereses
hipotecarios. 
de política monetaria. Utilizando datos mensuales de enero de 1995 a enero del 2007 calcularon 3 indicadores: la suma de los coeficientes autorregresivos de un proceso de orden $k$, la frecuencia de reversión a la media, $y$ un índice que asigna un mayor peso a los componentes que constituyen los mejores indicadores adelantados del comportamiento de la inflación ${ }^{11}$. Sin embargo, los autores recalcan que dado que existen varios factores que influyen en el proceso de toma de decisiones, no se espera que estos indicadores sean estadísticos suficientes para explicar las medidas de política monetaria en la Eurozona.

Por ejemplo, dentro de los principales hallazgos se destaca la presencia de una correlación de 0,73 entre la serie de coeficientes AR y la tasa principal de refinanciamiento del Banco Central Europeo ${ }^{12}$. Sin embargo, los autores aclaran que en términos de la interpretación:

"No estamos sugiriendo que el BCE ha reaccionado mecánicamente a este indicador específico de inflación subyacente; más bien, estamos sugiriendo que nuestro indicador de inflación subyacente, por sí mismo, está correlacionado con la perspectiva de mediano plazo de inflación sobre la cual reacciona el BCE”. (p.14)

Asimismo, se debe considerar otras limitaciones de esta metodología. Andrews y Chen (1994) argumentan que la suma de los coeficientes autorregresivos podría no ser capaz de distinguir entre dos series con patrones de impulso-respuesta diferentes: una con un incremento inicial fuerte y subsiguiente descenso rápido de la respuesta, $y$ otra con incremento inicial moderado $y$ descenso lento de la respuesta. Dias y Marques (2005) muestran que tampoco podría distinguir entre dos series donde una de ellas presenta un patrón cíclico.

Finalmente, otro resultado valioso de Bilke y Stracca (2008) que debe considerarse es la presencia de indicios que señalan cambios significativos a lo largo del tiempo en la persistencia de los componentes que conforman el HICP (Harmonised Index of Consumer Prices), el índice de referencia para el BCE en términos de su objetivo de inflación.

Para este propósito, se utilizaron las variaciones mensuales y anuales de los precios de los bienes y servicios que conforman la canasta IPC de julio del 2006 a diciembre del 2012. En algunas series, los indicadores finales tendrán menos observaciones, ya que será necesaria una muestra inicial para estimar las regresiones propuestas. Además, es importante señalar que a los datos no se les ha restado su media y se adecuará su especificación para considerar los quiebres estructurales detectados mediante la prueba de Bai-Perron (2003).

\section{a. Medida de reversión hacia la media}

Este índice calcula la persistencia a partir del número de veces que una serie cruza su media. Entre más veces cruza su media una serie de variación de precios de un artículo, más débil es la evidencia de persistencia para ese artículo. Cada serie de variaciones de precios se pondera por el inverso de este número $\left(1 / m_{i}\right)$, reescalando los pesos para que sumen uno. Además, se maneja una doble ponderación, manteniendo los pesos originales de la canasta. El indicador se calcula para el período julio-2006 a diciembre 2012.

Es importante señalar que este indicador se construye sólo con las variaciones mensuales de 288 de los 292 artículos de la canasta del IPC, ya que 4 componentes $^{13}$ (3 de ellos servicios

11 Este indicador fue construido basándose en la segunda sugerencia dada por Blinder (1997).

12 Los autores llegan a un resultado similar en el caso del indicador creado por medio de la reversión de la media.

13 Servicio de telefonía fija, teléfono celular, revisión técnica y licencia de conducir. 
regulados) fueron excluidos ya que el número de veces que cruzaron la media fue igual a cero, $y$ el ponderador estaría indefinido en estos cuatro casos. Nos referiremos a este indicador como R_2_cruce_medias.

El índice se construye siguiendo la metodología del cálculo del IPC por medio de las series $C_{t}^{i}$, donde los componentes se reponderan mediante $r_{i}=1 / m_{i}$. De esta forma,

$$
I_{t}^{\text {cruce }}=\sum_{n=1}^{292} C_{i}^{i^{*}}
$$

donde el costo $C_{t}^{i}$ de cada artículo es actualizado usando las variaciones mes contra mes del nivel del índice para el artículo $i$ en el mes $t$, reponderando mediante $r_{i}$.

\section{b. $\quad$ Suma de coeficientes Autorregresivos (AR)}

Para el caso de la suma de coeficientes AR se estiman 3 variantes de la ponderación: mediante el uso de estimaciones de coeficientes de un proceso autorregresivo de orden 1, mediante la suma de los coeficientes autorregresivos de procesos de orden $k, y$ mediante la suma de coeficientes autorregresivos con doble ponderación. Para el cálculo de las regresiones necesarias para obtener los coeficientes, la muestra inicial se fijó en 20 observaciones, por lo cual, los indicadores son estimados de marzo del 2008 a diciembre del 2012. Se excluyen del cálculo 6 series de precios de artículos ${ }^{14}$ ya que prácticamente no presentan cambios en las variaciones mensuales de sus precios.

En particular, la metodología del coeficiente autorregresivo de orden 1 sigue el mismo procedimiento propuesto por Cutler (2001), estimando la siguiente ecuación de forma recursiva con la serie de variaciones de precio de cada artículo de la canasta:

$$
\Delta p_{i, t}=\alpha_{i}+\beta_{i} \Delta p_{i, t-1}+\delta_{i} d_{i, t}+\varepsilon_{i, t}
$$

En (9) se ha introducido una variable de grada $d_{i, t}$ que es igual a 1 a partir de la fecha en la que se identificó cambio estructural en la serie de variaciones de precio mediante la prueba BaiPerron, con el fin de aislar de la estimación de $\beta_{i}$ el efecto del cambio estructural. En adelante al indicador calculado reponderando a partir de las estimaciones de $\beta_{i}$ se le llama R_1_AR1.

Si el coeficiente $\beta_{i}$ es negativo, se asigna un valor de cero puesto que, como se señaló anteriormente, un coeficiente menor a cero es indicativo de una persistencia baja. Posteriormente, los demás coeficientes son reescalados para sumar 1. En este caso, se genera un conjunto de ponderadores $r_{i}$ a partir de los cuales se calcula un nuevo indicador

$$
I_{t}^{A R 1}=\frac{\sum_{i=1}^{N} I_{t}^{i} r_{i}}{\sum_{i=1}^{N} r_{i}}
$$

donde $l_{t}^{i}$ representa el índice para el artículo $i$ en el mes $t$.

14 Servicio de teléfono fijo, teléfono celular, revisión técnica, licencia de conducir, periódicos y honorarios de abogados. 
Para la segunda variante de esta metodología, se sigue la propuesta de Bilke y Stracca (2008). La especificación se calcula de forma recursiva de la siguiente forma:

$$
\Delta p_{i, t}=\alpha_{i}+\sum_{k=1}^{n} \beta_{i, k} \Delta p_{i, t-k}+\delta_{i} d_{i, t}+\varepsilon_{i, t}
$$

donde se define como el que haga mínimo el criterio de Schwarz, y se incluye la variable dicotómica $d_{i, t}$ para aislar el efecto del cambio estructural en las series que así lo requieran. Luego, se procede a sumar los coeficientes. Si la suma es negativa se asigna un valor igual a cero, caso contrario, se mantiene su valor y se reescalan los coeficientes $r_{i}$ para que sumen 1 . Este indicador (R_1_AR) se calcula con el mismo procedimiento que R_1_AR1:

$$
I_{t}^{A R_{-} n}=\frac{\sum_{i=1}^{N} I_{t}^{i} r_{i}}{\sum_{i=1}^{N} r_{i}}
$$

donde $l_{t}^{i}$ representa el índice para el artículo $i$ en el mes $t$.

Finalmente, la tercera variante implica doble ponderación, de modo que utilizando los mismos pesos estimados para R_1_AR, se construye un nuevo índice de la siguiente forma:

$$
I_{t}^{\text {rep }}=\frac{\sum_{i=1}^{N} I_{t}^{i} g_{i}}{\sum_{i=1}^{N} g_{i}} \operatorname{con} g_{i}=w_{i} r_{i}
$$

Donde $w_{i}$ son los pesos originales del IPC. Identificaremos a esta medida como R_2_AR, donde el "2" hace referencia a la doble ponderación.

\section{c. Correlación de variaciones de precios por artículo con variaciones futuras del IPC}

Para esta medida se estima de forma recursiva la correlación de la serie de variaciones interanuales de cada ítem del IPC con las variaciones anuales del IPC un año después:

$$
\Delta I_{t}^{I P C}=\beta_{i} \Delta p_{i, t-1}+\varepsilon_{i, t-1}
$$

Si la correlación es negativa, se asigna un valor igual a cero y los demás coeficientes son reescalados para que sumen uno. Así, entre mayor sea la correlación con la inflación de un año después, mayor peso se asigna al producto, ya que este constituye un mejor indicador adelantado de la inflación futura. Finalmente, el índice se construye como:

$$
I_{t}^{\text {var_fut }}=\frac{\sum_{i=1}^{N} I_{t}^{i} r_{i}}{\sum_{i=1}^{N} r_{i}}
$$


donde $r_{i}$ es el peso reescalado según los datos arrojados por la correlación. A este indicador nos referiremos con R1_var_futura.

\section{d. Reponderación basada en el espectro de las series}

Otra medida de persistencia ampliamente utilizada es el espectro de la serie de inflación evaluado en la frecuencia cero ${ }^{15}$. El espectro de una serie estacionaria en covariancia $\pi_{t}$ puede expresarse en términos de sus autocovariancias $\gamma_{\mathrm{j}}$ como

$$
S_{\pi}(\omega)=\frac{1}{2 \pi}\left[\gamma_{0}+2 \sum_{j=1}^{\infty} \gamma_{j} \cos (\omega j)\right]
$$

por lo que el escalar $S_{\pi}(0)$ puede interpretarse como una medida de la autocovariancia de baja frecuencia de la serie ${ }^{16}$.

El espectro es una función continua, periódica, de valor real y no negativa de la frecuencia angular $\omega$ y está centrada alrededor de 0 . Por ello, el intervalo de valores de $[0, \pi]$ permite conocer el valor de $S_{\pi}(\omega)$ para cualquier $\omega$, por lo que la frecuencia angular suele representarse como una fracción del numeral $\pi$. Para una función periódica como $\cos (\omega \mathrm{j})$, cada componente de frecuencia $\omega=2 \pi f$ indica la rapidez del ciclo de la variable. La frecuencia $f=\omega / 2 \pi$ indica el número de ciclos completados en $2 \pi$ períodos, mientras que el período $p=1 / f=2 \pi / \omega$ indica el largo del ciclo. Por ejemplo, $\omega=0,5 \pi$ implica un período de $p=2 \pi / 0,5 \pi=4$ unidades de tiempo por ciclo. Nótese que valores bajos de $\omega$ se asocian con ciclos más largos, mientras que valores altos sugieren ciclos de menor duración. Dado que las frecuencias se representan como fracciones de $\pi$, en lo que resta de la sección $\omega$ se representará solamente con valores entre 0 y 1.

Una propiedad particularmente importante es que el área bajo el espectro entre $-\pi y \pi$ es igual a la variancia de la serie. En el contexto univariado usual, el análisis espectral permite entonces aproximar el monto de la variancia que está determinado por cada componente periódico, lo que indica la importancia relativa en la variancia de componentes transitorios frente a componentes más permanentes. Si las frecuencias bajas (ciclos más largos) agrupan la mayor parte de la variancia, eso indica una mayor influencia de las variaciones de más largo plazo. De manera análoga, una mayor contribución relativa de las frecuencias más altas sugiere una mayor influencia de ciclos cortos en la variabilidad de la serie.

Andrews y Chen (1994) indican que para el modelo AR(p) dado por

$$
\pi_{t}=\mu+\beta_{1} \pi_{t-1}+\ldots+\beta_{p} \pi_{t-p}+\varepsilon_{t} \quad \text { con } \varepsilon \square \operatorname{iid}\left(0, \sigma^{2}\right)
$$

el valor $S_{\pi}(0)$ es una transformación monotónica de la suma de los coeficientes autorregresivos $\rho=\sum_{i=1}^{p} \beta_{i}$, donde $S_{\pi}(0)=\sigma^{2} /(1-\rho)^{2}$, por lo que la persistencia medida de esta forma esencialmente depende del valor de $\rho$. Sin embargo, como mencionan Dias y Marques (2005), el uso de este indicador no sería adecuado para medir cambios en persistencia a lo largo de un período, por cuanto éstos podrían originarse tanto en $\rho$ como en $\sigma^{2}$. Esto haría problemático utilizar este estimador de

15 Ver, entre otros, Cogley y Sargent (2001) y Cogley y Sargent (2005) para el caso de los EE.UU; Capistrán y RamosFrancia (2009) para un conjunto de países latinoamericanos; D’Amato, Garegnani y Sotes (2008) para Argentina; y Rodríguez (2011) para el caso de Costa Rica. (1994), capítulo 6, y Granger y Hatanaka (1971). 
persistencia para reponderar un índice de precios en diferentes momentos. Adicionalmente, $S_{\pi}(0)$ no tiene un rango de variación claramente definido, como es el caso con .

Se considera que utilizar $S_{\pi}(0)$ como el indicador de persistencia a partir del cual reponderar los artículos de la canasta IPC tiene una limitación adicional importante: no se sensibiliza la ponderación a casos en los que la mayoría de la variancia de la serie se ubica en torno a frecuencias distintas a cero. Utilizar como indicador de persistencia el valor del espectro en la frecuencia cero en vez de calcularlo como relativo al valor máximo podría introducir distorsiones en la importancia relativa asignada a los artículos, especialmente en casos donde las variaciones de corto plazo explican la mayoría de la variancia en los precios. Por ejemplo, dos series con el mismo valor para $S_{\pi}(0)$ recibirían la misma ponderación aun si para una de ellas el valor máximo del espectro ocurre en una frecuencia $\omega^{\max }>0$, correspondiente a ciclos de menor duración. Además, se considera que en la ponderación debería incorporarse información sobre el valor de la frecuencia $\omega^{\max }$. Si el interés es reponderar de acuerdo con la importancia que tienen los ciclos de más largo plazo en la variabilidad de la serie, un artículo cuyo espectro tiene un máximo en $\omega=0,25$ (correspondiente a ciclos de 8 unidades de tiempo) debería recibir una ponderación menor a uno cuyo espectro tiene un máximo en $\omega=0,5$ (correspondiente a ciclos de 4 unidades de tiempo). Se propone reponderar los pesos mediante un factor que considere más información del espectro que solamente su valor en la frecuencia cero. La medida de inflación en este caso vendría dada por:

$$
\pi_{t}=\frac{\sum_{i=1}^{N} \pi_{t}^{i} g_{i}}{\sum_{i=1}^{N} g_{i}} \operatorname{con} g_{i}=w_{i} r_{i}
$$

donde el factor de reponderación es

$$
r_{i}=\frac{S_{\pi}^{i}(0)}{S_{\pi}^{i}\left(\omega_{i}^{\max }\right)}\left(1-\omega_{i}^{\max }\right)
$$

En (19), la razón $\frac{S_{\pi}^{i}(0)}{S_{\pi}^{i}\left(\omega_{i}^{\max }\right)}$ es un indicador de la importancia relativa de los ciclos asociados con la frecuencia donde ocurre el máximo en comparación con la frecuencia tradicionalmente utilizada como indicador del largo plazo. El factor $\left(1-\omega_{i}^{\max }\right)$ ajusta el valor de la razón anterior de acuerdo con la posición del máximo en el intervalo de frecuencias angulares [0,1], de modo que el valor de $r$ se reduce conforme el máximo ocurre a frecuencias más altas. Nótese además que el esquema de reponderación propuesto no depende del valor de la variancia $\sigma^{2}$, sino que se basa en un número relativo entre 0 y 1 , por lo que cambios en $\sigma^{2}$ que no se acompañen de un cambio en la forma del espectro no afectarían la reponderación.

Si el máximo del espectro ocurre en la frecuencia cero, esto corresponde al caso en el que la mayor parte de la variabilidad de los precios del artículo se asocia con ciclos de largo plazo, por lo que el ponderador tendrá el valor máximo posible de $r=1$ y el artículo conservará su peso $\omega_{i}$ intacto. En otro caso, el valor del ponderador va a disminuir dependiendo de cuán alta sea la frecuencia en la que se ubica el máximo del espectro y de cuán distinto sea su valor en comparación con el de la frecuencia cero. Por ejemplo, si dos series tienen un máximo en la misma frecuencia $\omega^{*} \neq 0$, la serie que recibiría una ponderación menor sería la del espectro con mayor distancia 
entre su máximo y su valor en la frecuencia cero, por cuanto en ese caso la frecuencia $\omega^{*}$ tendría una importancia relativa mayor ${ }^{17}$.

El gráfico 1 ilustra los resultados de reponderar usando el método propuesto en (18)-(19) y usando el indicador $S_{\pi}(0)$. El espectro de la serie 1 tiene un máximo en la frecuencia $\omega=0$, mientras que el de la serie 2 lo tiene en $\omega=0,1429$. Si se utilizara $S_{\pi}(0)$ para realizar la reponderación, los pesos finales (reescalados) de los artículos serían bastante similares, puesto que sus valores en la frecuencia cero son muy cercanos, mientras que el esquema propuesto asigna menos peso a la serie 2, cuyo máximo se ubica en una frecuencia más alta, correspondiente a ciclos más cortos.

GRÁFICO 1

REPONDERACIÓN CON MÉTODOS BASADOS EN ESPECTRO DE LAS SERIES

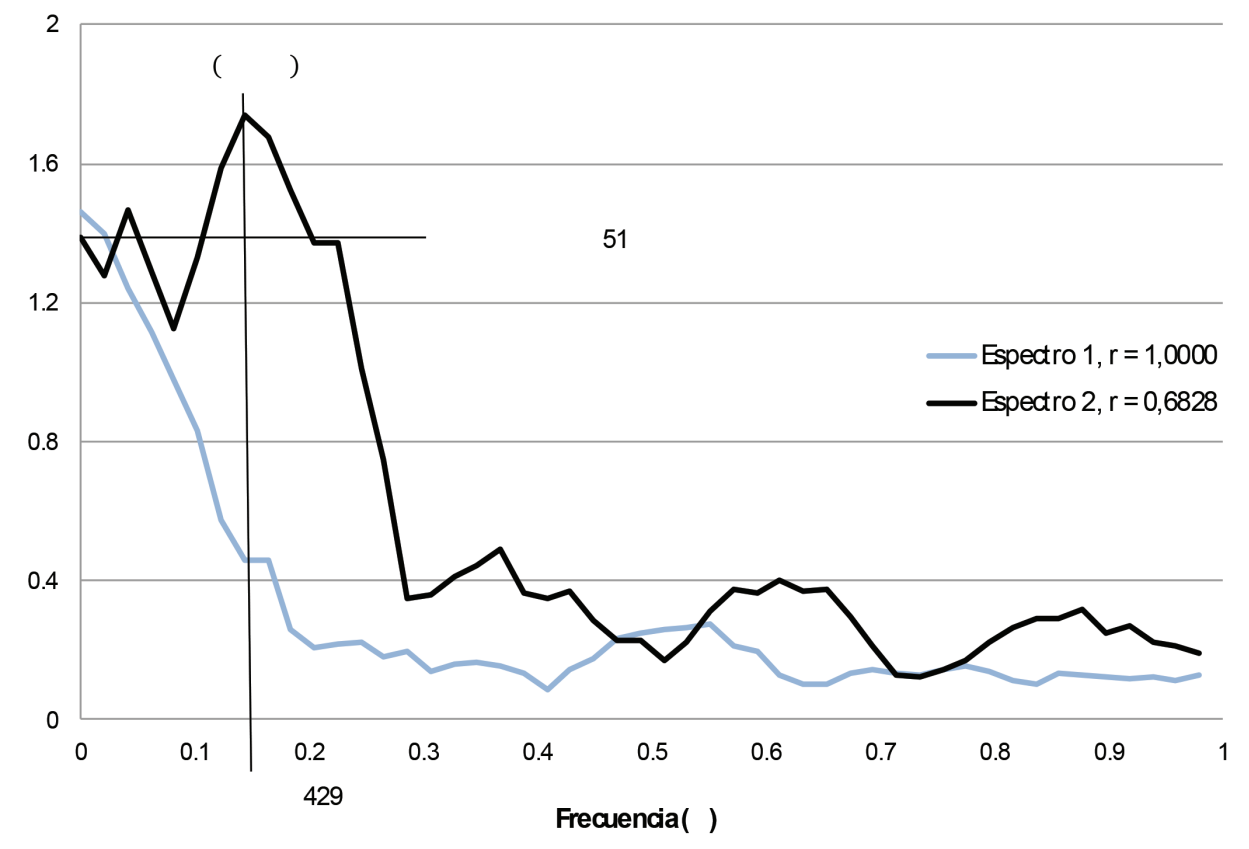

\begin{tabular}{lcccccc}
\hline & & & & & Peso final \\
\hline & $\left.S_{f}^{i}\right) 1 *$ & $\left.S_{f}^{i}\right) \max _{*}$ & $i^{\max }$ & $r_{i}$ & Indicador frecuencia œro & Método propuesto \\
\hline Espectro 1 & 1,4631 & 1,4631 & 0,0000 & 1,0000 & $0,30 \%$ & $0,45 \%$ \\
Espectro 2 & 1,3851 & 1,7387 & 0,1429 & 0,6828 & $0,28 \%$ & $0,27 \%$ \\
\hline
\end{tabular}

Fuente: elaboración propia.

Para realizar la reponderación mediante este método se utilizó las series de variaciones mensuales de precio de los 292 artículos de la canasta IPC para el período julio 2006 - diciembre 2012. El espectro de cada una de las series se estimó utilizando una ventana plana (flat window), una ventana tipo tent $y$ una cuadrática, a fin de considerar posibles variaciones en la forma del espectro estimado $^{18}$. Con los datos de los espectros estimados con cada tipo de ventana se calculó una serie

17 Solo si $\omega^{\max }$ se tendría que $r=0$. Esto corresponde al mínimo posible de unidades de tiempo por ciclo: $\mathrm{p}=2$ (frecuencia de Nyquist).

18 Para una discusión de los métodos de estimación del espectro véase Hamilton (1994), capítulo 6, y Granger y Hatanaka (1971). 
de inflación subyacente mediante el esquema propuesto en (18)-(19). Además, para incorporar la información de todos los espectros estimados, con el promedio simple de los $r_{i}$ resultantes de cada estimación se calculó una serie adicional de inflación subyacente, a la que en adelante se identifica como combinada. Estos indicadores de inflación subyacente se denominan R_2_espect_flat, R_2_ espect_tent, R_2_espect_quad y R_2_espect_comb, respectivamente.

El cuadro 4 resume los indicadores de inflación subyacente calculados mediante reponderación.

CUADRO 4

INDICADORES DE REPONDERACIÓN POR PERSISTENCIA SOMETIDOS A EVALUACIÓN

\begin{tabular}{|c|c|c|c|}
\hline & Tipo de ponderación & Ponderador de persistencia & $\begin{array}{l}\text { Período de } \\
\text { cálculo }\end{array}$ \\
\hline R1_var_futura & \multirow{3}{*}{ Por persistencia } & Correlación con variación futura de la inflación & $\begin{array}{l}2006: 07- \\
2012: 12\end{array}$ \\
\hline R_1_AR1 & & \multirow{2}{*}{ Coeficiente autorregresivo de un AR(1) } & \multirow{3}{*}{$\begin{array}{l}\text { 2008:03- } \\
2012: 12\end{array}$} \\
\hline R_1_AR & & & \\
\hline R_2_AR & \multirow{6}{*}{$\begin{array}{l}\text { Por persistencia } \\
\text { y peso en consumo }\end{array}$} & Suma de coeficientes autorregresivos & \\
\hline R_2_cruce_medias & & Inverso del número de veces que serie cruza su media & \multirow{5}{*}{$\begin{array}{l}2006: 07 \\
2012: 12\end{array}$} \\
\hline R_2_espect_flat & & & \\
\hline R_2_espect_tent & & Basado en espectro $r_{i}=\frac{S_{\pi}^{i}(0)}{S^{i}\left(\omega^{\max }\right)}\left(1-\omega_{i}^{\max }\right)$ & \\
\hline R_2_espect_quad & & & \\
\hline R_2_espect_comb & & Promedio de ponderadores basados en espectro & \\
\hline
\end{tabular}

Fuente: elaboración propia.

\section{DESCRIPCIÓN DE LOS INDICADORES CALCULADOS}

Este apartado describe la evolución de los indicadores estimados y se les compara con los índices utilizados actualmente para medir inflación en el Banco Central de Costa Rica (ISI, IMT e IPC). Los indicadores propuestos se presentan en secciones separadas de acuerdo con su enfoque metodológico (exclusión y reponderación), mientras que en el apartado final se realiza una comparación de la reponderación de los pesos según volatilidad y persistencia.

\section{Medidas de exclusión}

Se construyeron 291 series de inflación subyacente con el método de exclusión por volatilidad de productos y se seleccionaron 11 series bajo el criterio del menor error cuadrático medio con respecto a la tendencia del IPC para el período julio 2006 a diciembre del 2011. Estas series excluyen un rango de 41 a 51 bienes y servicios, los cuales mostraron la mayor variabilidad en los precios históricos. Asimismo, se incluyó dentro de esta categoría 4 medidas de exclusión por grupos y la IMT como medida de referencia. 


\section{Evolución de los indicadores de exclusión por producto (ISI_j)}

En este apartado se presentan las series ISI_j propuestas y su comparación con el ISI vigente. La selección de las 11 series se basa en el ordenamiento de su ajuste con respecto a una medida de tendencia calculada con datos mensuales de julio del 2006 a diciembre del 2011. Para este propósito, se utiliza una media móvil de 24 meses para aproximar la tendencia de la inflación, seleccionándose las 10 series ubicadas alrededor de la serie que presenta el mejor ajuste (ISI_46). Para su identificación, se han nombrado las 11 series propuestas con números del 41 al 51, donde este número hace referencia a la cantidad de bienes y servicios que fueron excluidos para su cálculo.

Con el fin de ilustrar cambios en la lista de los productos más volátiles de la canasta del IPC, se realizó ordenamientos de las variaciones de precio de los artículos de la canasta en orden descendente de acuerdo con su volatilidad y se determinó los 55 artículos más volátiles de la canasta IPC en cada caso ${ }^{19}$. De seguido, se identificó los productos comunes a ambos ordenamientos y los productos específicos de cada uno. El resultado de esta identificación se presenta en el cuadro 5. La primera columna presenta los productos que están incluidos en ambos ordenamientos (con datos a 2006 y a 2011); la segunda, los que únicamente forman parte del ordenamiento original y la tercera los que entran como parte del nuevo ordenamiento. Agrupando los elementos de la primera y de la segunda columna se tiene la lista de los 55 bienes y servicios que son eliminados actualmente para el cálculo del ISI.

Hay 33 productos que forman parte de ambos ordenamientos, y que se pueden considerar como los que presentan mayor variabilidad. De estos 33 productos, la mayoría forman parte del grupo de Alimentos (23). Los restantes pertenecen a Educación (4), Combustibles (3), Servicios a la vivienda (2) y Servicios de transporte (1). Además, 6 de estos bienes y servicios son regulados. En relación con el ordenamiento actualizado, los productos agrícolas presentan las volatilidades más altas, incluyendo productos de este tipo que no figuraban en el ordenamiento con datos a 2006, como sandía, uva o manzana ${ }^{20}$. Dentro de los bienes regulados, el arroz entra a formar parte de la nueva lista.

19 El cálculo de la volatilidad se realiza obteniendo el error cuadrático medio de cada serie en comparación con la medida de tendencia de inflación, que corresponde a un promedio móvil centrado de 24 meses, por lo que el último dato disponible es a diciembre de 2011. Se utiliza datos de enero 1996 a diciembre de 2011. La lista consta de 55 productos por cuanto ese es el número de artículos excluidos para el cálculo del ISI vigente.

20 Los bienes de origen agrícola se ven directamente afectados por factores climáticos y de estacionalidad, por lo que es usual que exhiban mayor volatilidad en sus precios. 
CUADRO 5

PRODUCTOS CON MAYOR VOLATILIDAD HISTÓRICA

\begin{tabular}{|c|c|c|}
\hline Productos en ambos ordenamientos & $\begin{array}{l}\text { Productos en ordenamiento } \\
\text { con datos a jul-2006 }\end{array}$ & $\begin{array}{l}\text { Productos en ordenamiento } \\
\text { con datos a dic- } 2011\end{array}$ \\
\hline Tomate & Tortillas de maíz & Sandia \\
\hline Vainica & Chuleta de cerdo & Boleto aéreo \\
\hline Cebolla & Mgos de fruta & Uva \\
\hline Chile dulce & Bebidas gaseosas & Aguacate \\
\hline Pepino & Guaro & Unidad de respaldo magnético \\
\hline Papa & Ggarrillos & Honorarios a abogado \\
\hline Oulantro & Limpieza de vías & Juguete para niño \\
\hline Limón ácido & Recolección de basura & Harina de trigo \\
\hline Pepollo & Servicio doméstico & Hospedaje \\
\hline Papaya & Exámenes de laboratorio & Cámara fotográfica \\
\hline Chayote & Uantas para automóvil & Paquetes turisticos \\
\hline Huevos & Cambio de aceite & Pastas \\
\hline Zanahoria & Afinamiento de motor & Manzana \\
\hline Ajo & Ajuste de frenos & Papas tostadas \\
\hline Yuca & Revisión técnica de automóviles & Manteca \\
\hline Lechuga & Pasaje en autobús urbano & Arroz \\
\hline Gas licuado & Servicio de teléfono celular & Costilla de cerdo \\
\hline Gasolina & Servicio de teléfono fijo & Alas de pollo \\
\hline Bote & Servicio de Internet & Aceite \\
\hline Diésel & Educación superior & Revistas \\
\hline Piña & Qaderno & Impresora \\
\hline Texto universitario & Sombrilla & Qrso de computación \\
\hline \multicolumn{3}{|l|}{ Naranja } \\
\hline \multicolumn{3}{|l|}{ Transporte en taxi } \\
\hline \multicolumn{3}{|l|}{ Pátano } \\
\hline \multicolumn{3}{|l|}{ Servicio de agua } \\
\hline \multicolumn{3}{|l|}{ Frijoles } \\
\hline \multicolumn{3}{|l|}{ Harina de maíz } \\
\hline \multicolumn{3}{|l|}{ Educación preescolar } \\
\hline \multicolumn{3}{|l|}{ Educación secundaria } \\
\hline \multicolumn{3}{|l|}{ Educación primaria } \\
\hline \multicolumn{3}{|l|}{ Posta de cerdo } \\
\hline Servicio de electricidad & & \\
\hline
\end{tabular}

Fuente: elaboración propia. 
Los gráficos 2 y 3 presentan las variaciones interanuales de las once series ISI_j cuyas propiedades se someterán a revisión. Además, se agregó el IPC, el ISI y el IMT que son las medidas utilizadas actualmente, y que servirán como marco de referencia.

Las 11 series ISI propuestas tienen una evolución muy similar y son menos volátiles que el IPC. Esto es un resultado esperado, ya que se están eliminando los componentes con mayor variabilidad relativa. Además, se puede apreciar que todas las series ISI_j se encuentran por debajo del IMT para el período considerado. De la misma forma, se observa que en varios tramos el ISI se encuentra por debajo de todas las series nuevas, principalmente a partir de abril del 2009, lo que podría ser indicio de sesgo en la estimación.

Dentro de las series propuestas, la ISI_46 parece alejarse más de las otras ISI_j en varios períodos. Esto se debe a que la ISI 46 excluye los 45 componentes que excluye el ISI_45 más el servicio de electricidad que es un servicio regulado. Este representa un 3,37\% de la canasta del IPC y es uno de los componentes con mayor peso.

GRÁFICO 2

INDICADORES ISI_J DE EXCLUSIÓN POR PRODUCTO, INFLACIÓN SEGÚN IPC, INFLACIÓN SEGÚN ISI E INFLACIÓN SEGÚN IMT

Variaciones interanuales

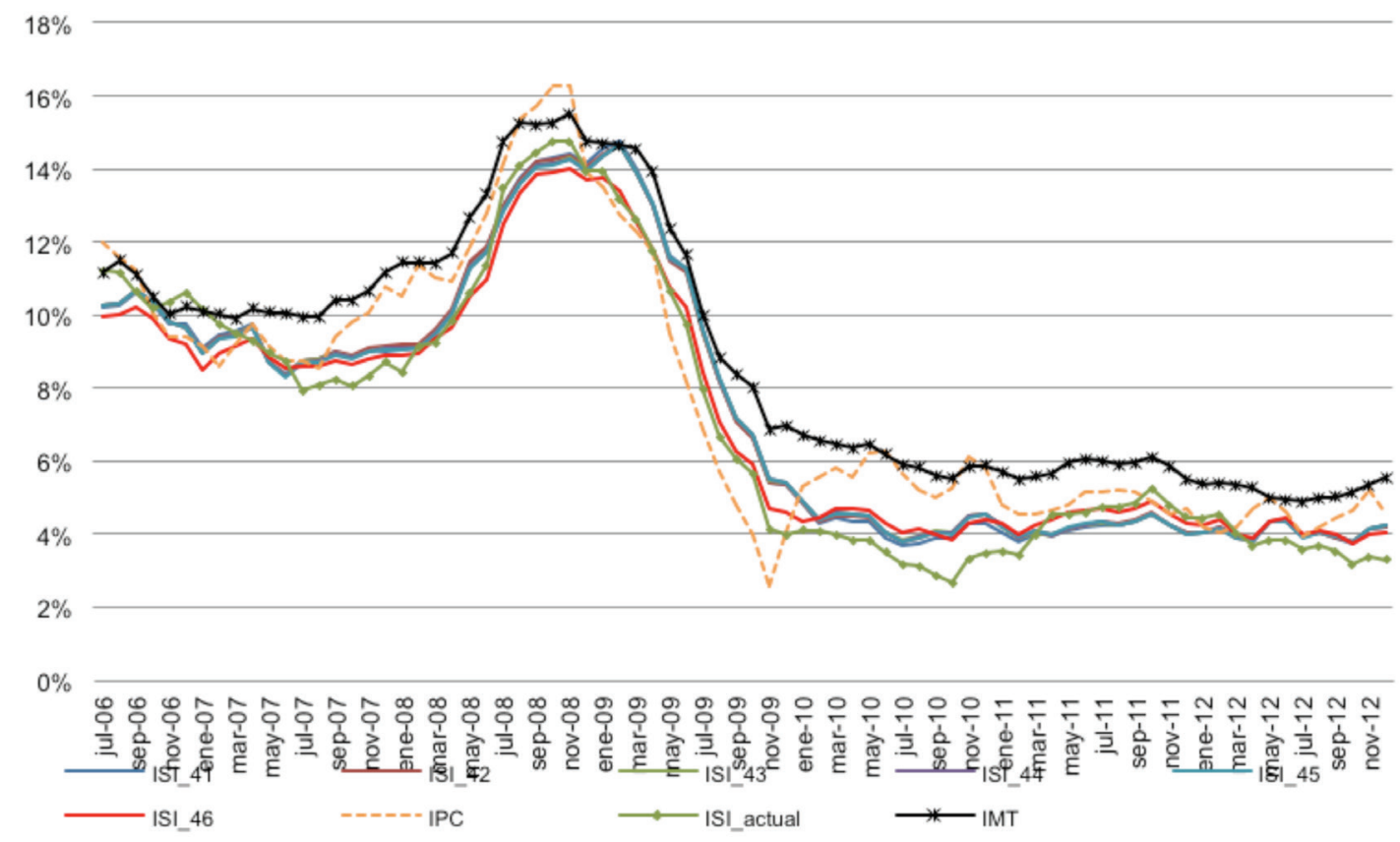

Fuente: elaboración propia. 
GRÁFICO 3

INDICADORES ISI_J DE EXCLUSIÓN POR PRODUCTO, INFLACIÓN SEGÚN IPC, INFLACIÓN SEGÚN ISI E INFLACIÓN SEGÚN IMT

Variaciones interanuales

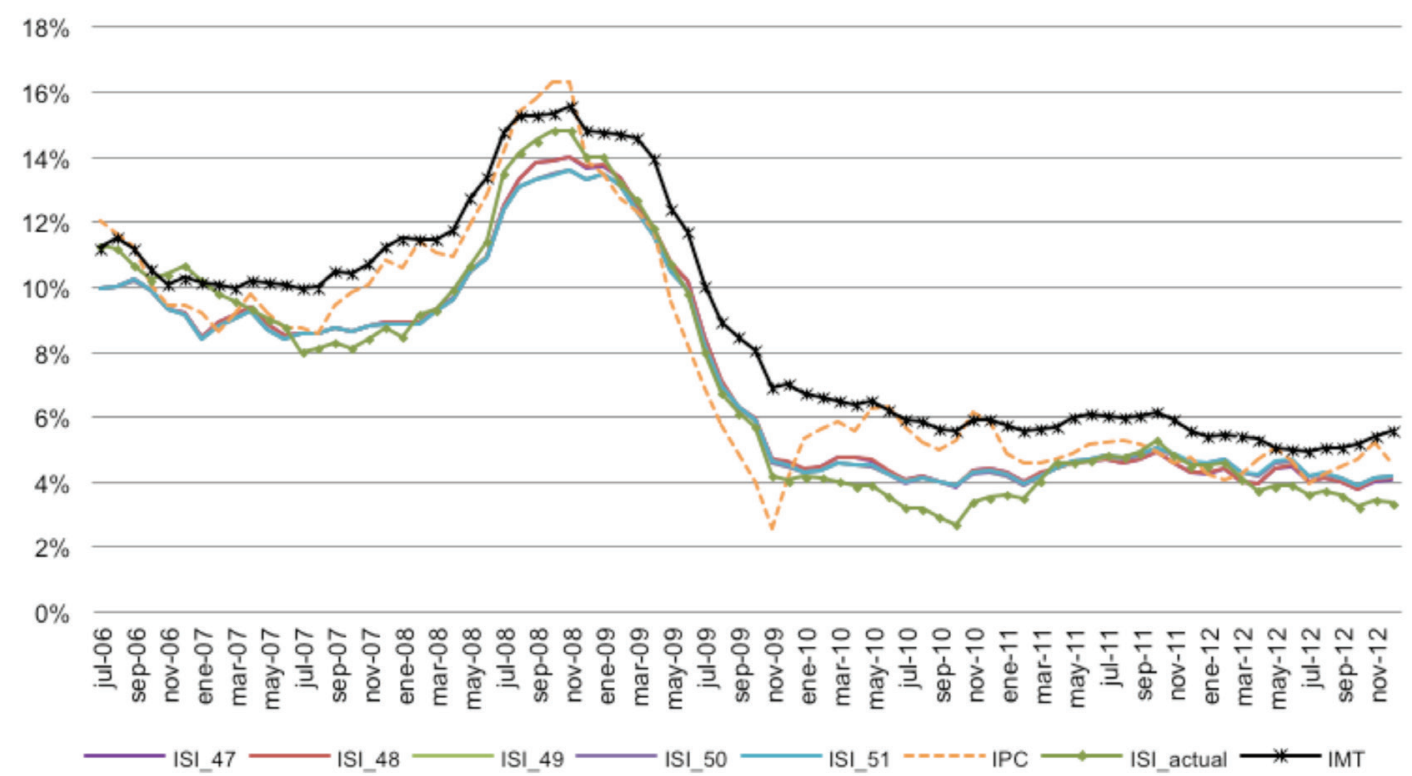

Fuente: elaboración propia.

Evolución de las series de exclusión por categorías de artículos

El gráfico 4 muestra las variaciones interanuales de las series estimadas por medio de la exclusión por categorías. Las series se encuentran más alejadas entre sí que en el caso de las series ISI_j, pero en general tienen una misma tendencia. Además, se puede observar que estas medidas se han ubicado entre los resultados del IMT y el ISI, especialmente de abril del 2009 hacia adelante.

En general, la tendencia no parece alejarse del IPC. No obstante, para los últimos 6 meses del 2012, el IPCX y el IPCX3 han mostrado una tendencia creciente similar a la de la IMT. Por el contrario, el IPCX1 y el IPCX2 señalan una tendencia decreciente semejante a la del ISI. 
GRÁFICO 4

SERIES DE EXCLUSIÓN POR GRUPOS, INFLACIÓN SEGÚN IPC, INFLACIÓN

SEGÚN ISI E INFLACIÓN SEGÚN IMT

Variaciones interanuales

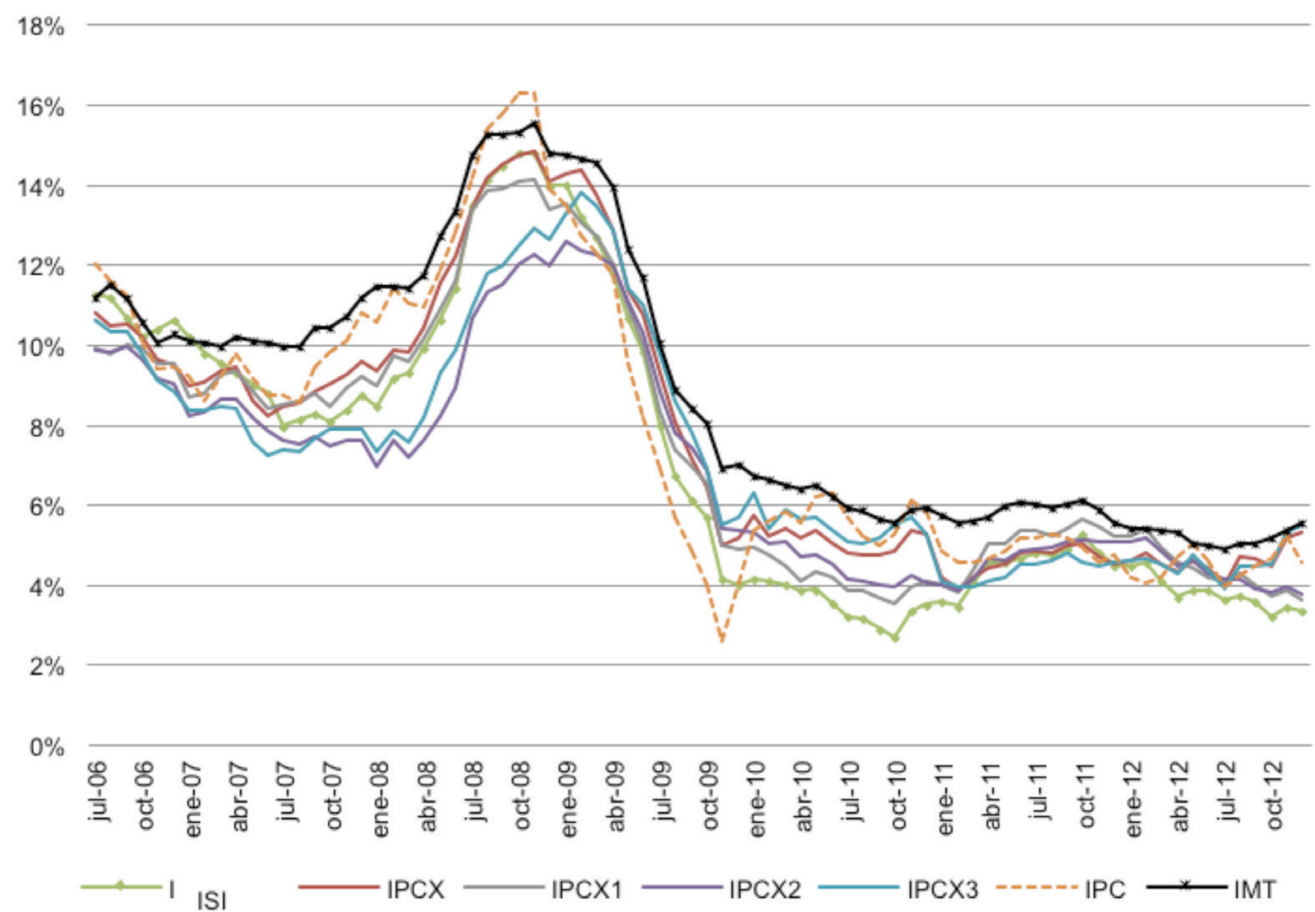

Fuente: elaboración propia.

\section{Medidas de reponderación}

En este apartado se presenta una descripción de la evolución de las 15 medidas de reponderación calculadas, separando las series en cuatro grupos: medidas reponderadas usando estimaciones del espectro (4), usando estimaciones de volatilidad (6), usando coeficientes auto-regresivos (3) y otras medidas (2).

\section{Evolución de las medidas basadas en estimación del espectro}

En general, las series construidas mediante reponderación basada en estimaciones del espectro de las series de variaciones en precio muestran un comportamiento más suave con respecto a lo observado en el IPC. En el gráfico 5 se pueden distinguir tres períodos en la evolución de los indicadores. Durante el periodo julio del 2007 a julio del 2009 las cuatro series se ubican por encima de los índices vigentes de inflación, alcanzando un máximo en octubre del 2008 (por encima del 18\%). A partir de julio del 2009 y hasta julio del 2011, las series se ubican por encima del ISI pero por debajo del IMT. Finalmente, de julio del 2011 hasta diciembre del 2009, las estimaciones se han aproximado mucho más al comportamiento del IMT, alejándose del comportamiento del ISI. 
GRÁFICO 5

SERIES REPONDERADAS POR ESPECTRO, INFLACIÓN SEGÚN IPC, INFLACIÓN SEGÚN ISI E INFLACIÓN SEGÚN IMT Variaciones interanuales

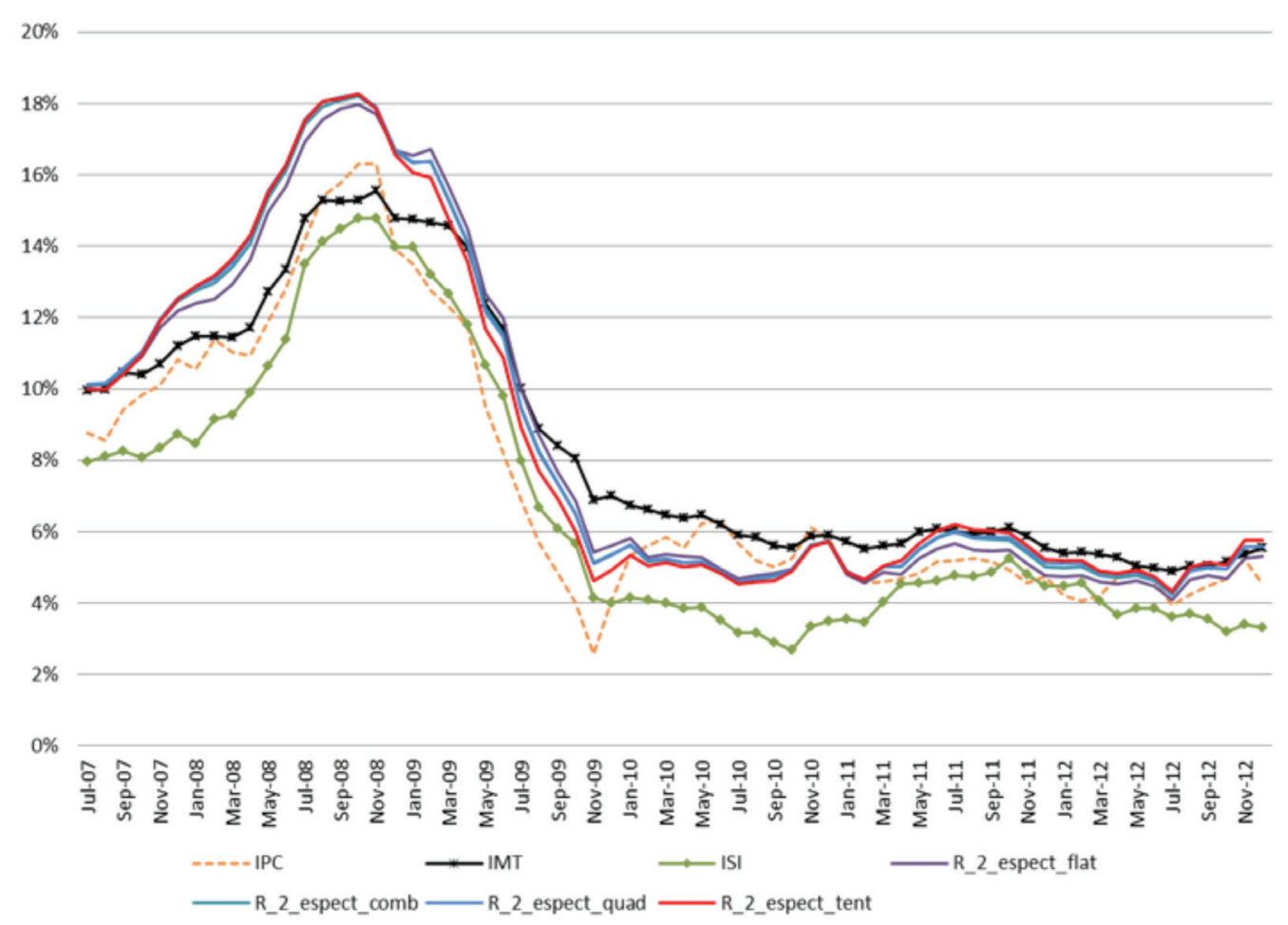

Fuente: elaboración propia.

Evolución de las medidas de reponderación por volatilidad

Las series calculadas a partir de estimaciones de variancias móviles son más cortas, como resultado de la propia metodología y de la revisión y modificación del cálculo del IPC en julio del 2006. Esto se puede apreciar en el gráfico 6, donde los primeros datos para estos indicadores empiezan en febrero del 2009.

En particular, las series calculadas mediante el criterio de reponderación según el inverso de la desviación estándar presentan un comportamiento relativamente estable. Caso contrario, las series obtenidas a partir de la metodología del inverso de la variancia móvil muestran un comportamiento más errático que el resto, especialmente para el caso asociado con la variancia móvil a 24 meses; por lo cual, podrían ser necesarias ventanas móviles más grandes para obtener series más estable. 
GRÁFICO 6

SERIES REPONDERADAS POR VOLATILIDAD, INFLACIÓN SEGÚN IPC, INFLACIÓN SEGÚN ISI E INFLACIÓN SEGÚN IMT

Variaciones interanuales

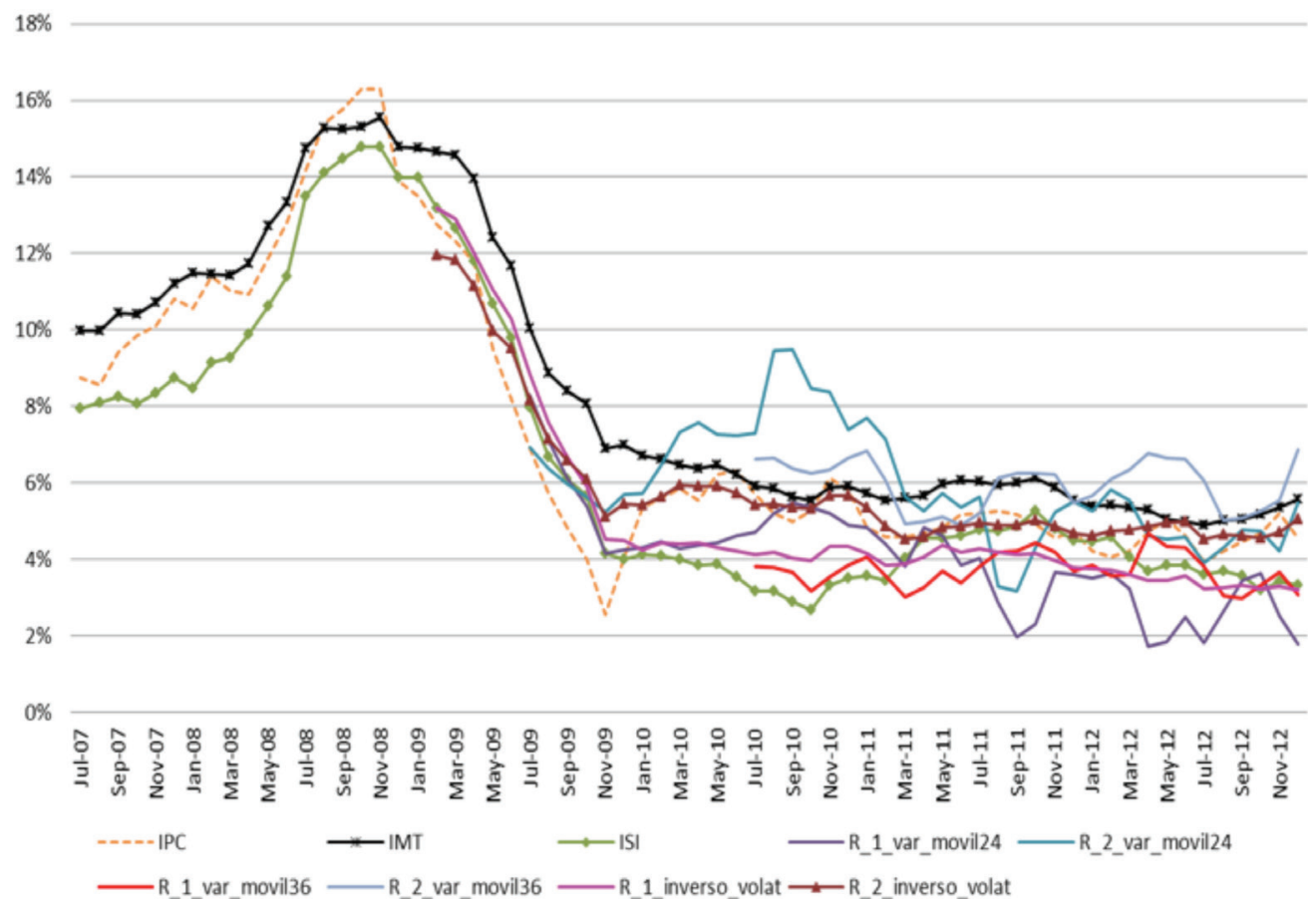

Fuente: elaboración propia.

\section{Evolución de las medidas reponderadas mediante coeficientes autorregresivos}

El gráfico 7 presenta las estimaciones bajo el método de coeficientes autorregresivos. En particular, estas series presentan mayores discrepancias con respecto a los indicadores que se utilizan actualmente. En especial, llama la atención el período de deflación sugerido por estos indicadores de junio del 2009 a febrero del 2010, aun cuando sea congruente con un menor crecimiento de los precios según los indicadores vigentes. Esta conducta podría señalar limitantes en la aplicabilidad de esta metodología para el caso de Costa Rica.

Asimismo, es importante notar que la tendencia que siguen las series con respecto a la inflación IPC no es tan fácilmente distinguible como en casos anteriores, $y$ en algunos periodos hay notables divergencias entre ellas y mayor volatilidad con respecto a la inflación IPC. 
GRÁFICO 7

SERIES REPONDERADAS POR COEFICIENTES AUTORREGRESIVOS, INFLACIÓN SEGÚN IPC, INFLACIÓN SEGÚN ISI E INFLACIÓN SEGÚN IMT Variaciones interanuales

$20 \%$

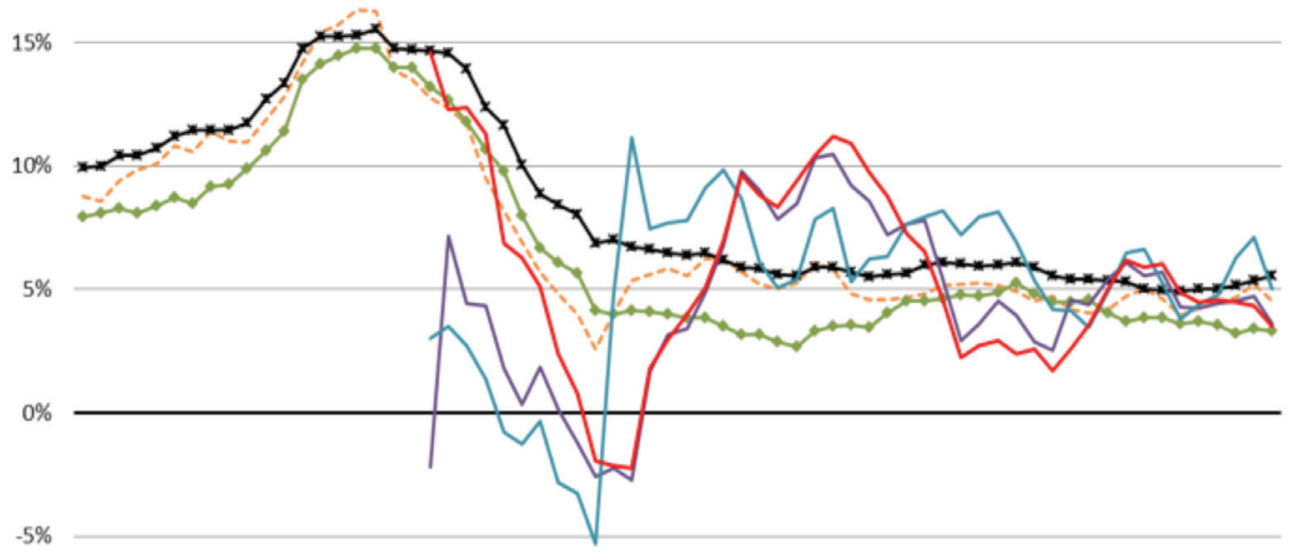

$-10 \%$

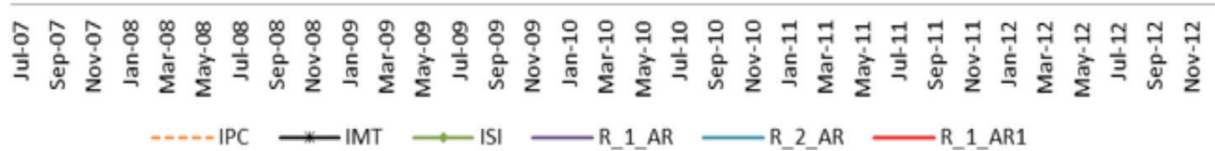

Fuente: elaboración propia.

Evolución de otras medidas de reponderación: cruce de medias y correlación con inflación futura

En el gráfico 8, el cruce de medias exhibe un comportamiento similar a la inflación IPC, alejándose de la trayectoria del ISI. Por otra parte, la serie asociada a la correlación futura presenta cambios más pronunciados que el IPC y no parece seguir el comportamiento de ninguno de los otros indicadores, especialmente de julio del 2010 en adelante. 
GRÁFICO 8

SERIES DE REPONDERACIÓN POR CRUCE DE MEDIAS Y CORRELACIÓN CON INFLACIÓN FUTURA, INFLACIÓN SEGÚN IPC, INFLACIÓN SEGÚN ISI E INFLACIÓN SEGÚN IMT

Variaciones interanuales

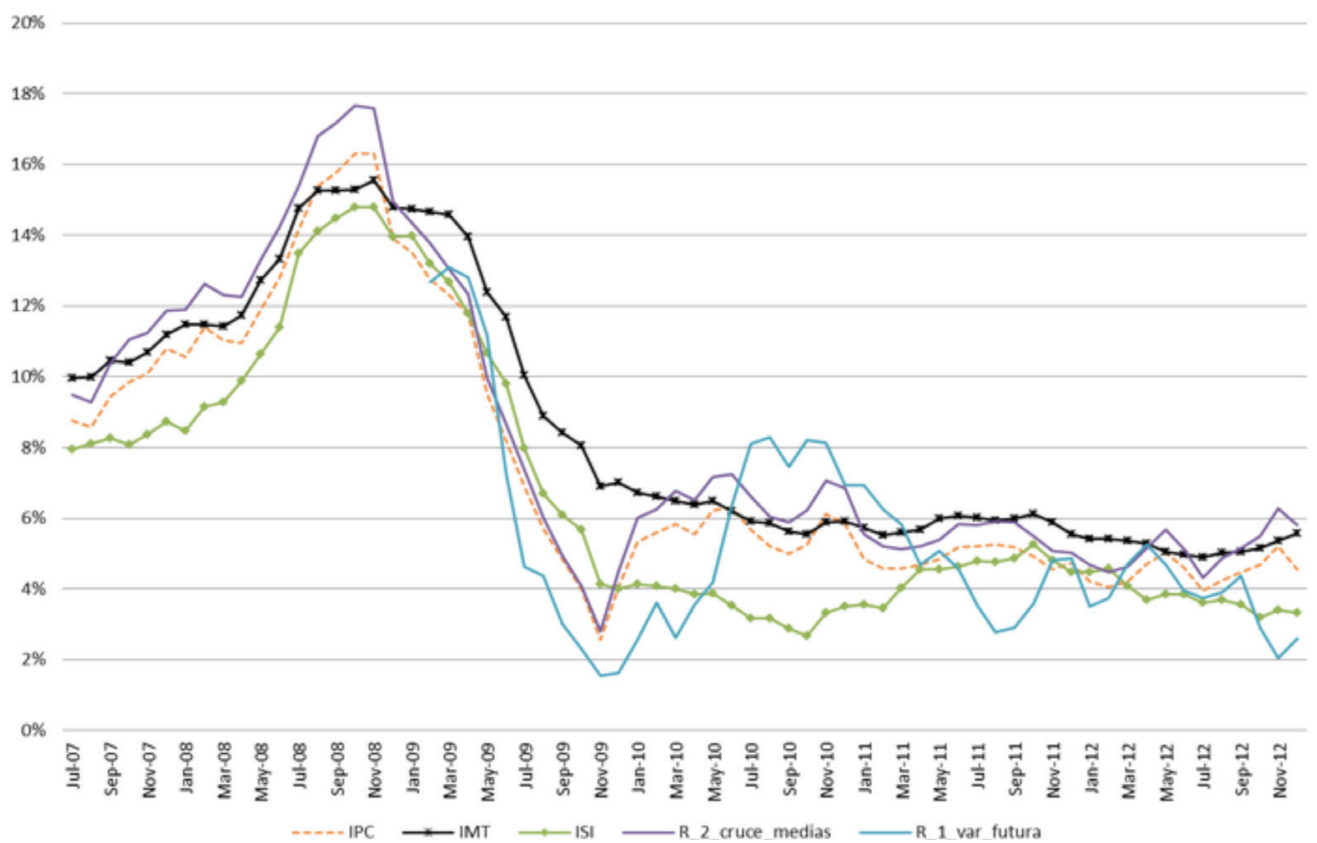

Fuente: elaboración propia.

\section{Pesos por persistencia, por volatilidad y según el IPC}

En esta sección se presenta un análisis de las diferencias en la asignación de pesos en varias de las medidas de inflación subyacente reponderadas por volatilidad y por persistencia. El gráfico 9 muestra el contraste entre las ponderaciones originales de la canasta $y$ los pesos asignados por medio del enfoque de persistencia basado en análisis espectral.

Lo primero a señalar es que existen 7 bienes que representan el $27,45 \%$ de la canasta de consumo. Esto implica que variaciones asociadas a estos 7 productos tienen impactos relativamente significativos en el cálculo del IPC. Sin embargo, 3 de estos productos (gasolina, adquisición de vehículos y pasaje en autobús urbano) presentan una persistencia baja, especialmente la gasolina, por lo que su peso en el cálculo del indicador reponderado resulta considerablemente menor, como permite distinguir la línea de $45^{\circ}$. También se da el caso de ítems con una importancia alta en el IPC que incrementan su ponderación en el indicador de persistencia incluyen el casado, el alquiler de vivienda, el servicio doméstico y el servicio de electricidad ${ }^{21}$.

\footnotetext{
21 Se presenta las ponderaciones correspondientes a un espectro estimado con ventana flat, pero se obtiene resultados
} similares al utilizar estimación mediante ventana cuadrática o tipo tent. 


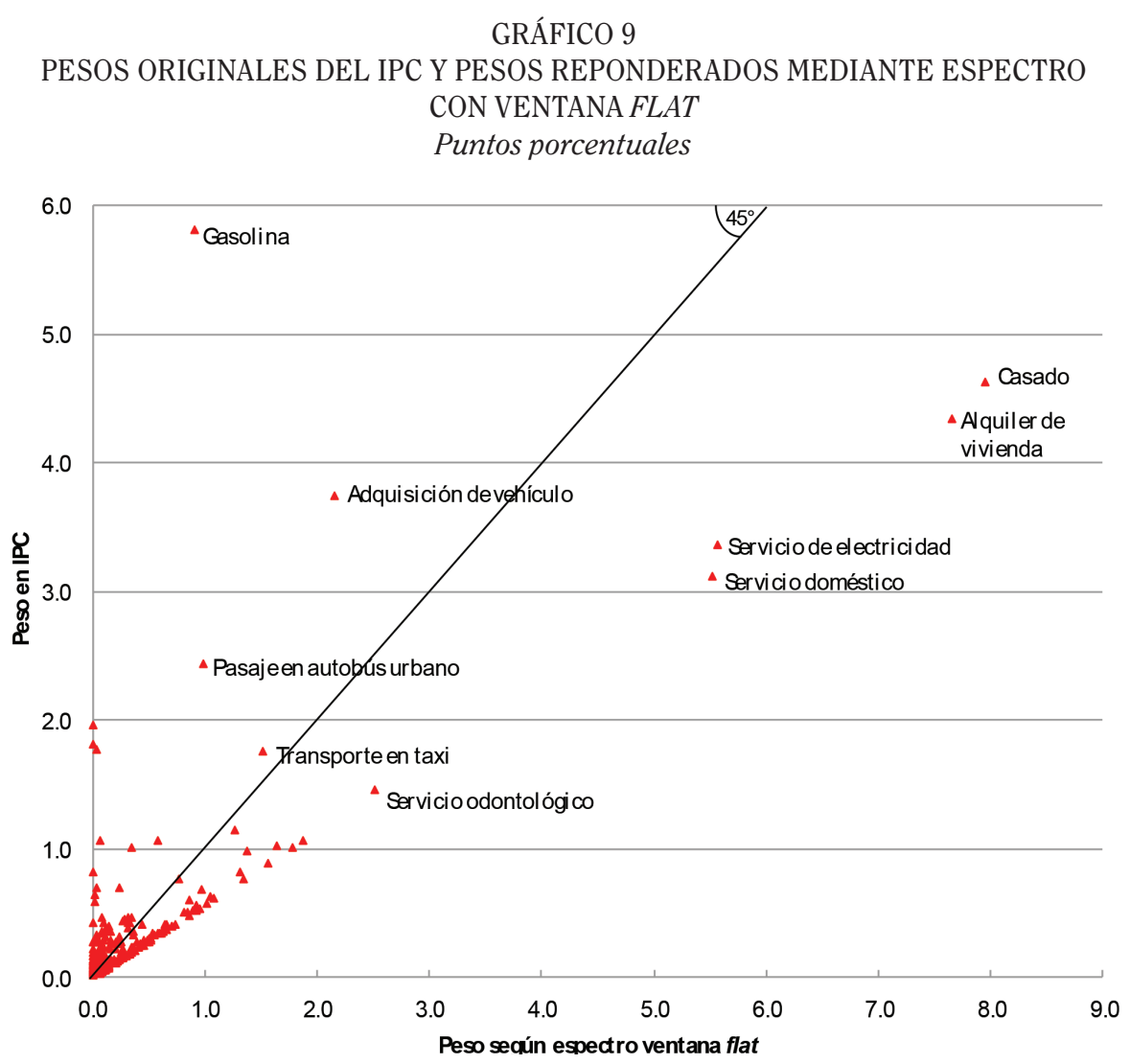

Fuente: elaboración propia.

El gráfico 10 realiza el mismo ejercicio considerando la asignación de pesos para diciembre del 2012 según el inverso de la volatilidad histórica para cada uno de los bienes y servicios. En este caso, el eje horizontal se interpreta a la inversa: los productos más volátiles se ubican a la izquierda $y$ los menos volátiles a la derecha.

En términos relativos, la gasolina presenta una volatilidad alta, $y$ por ende recibe una ponderación baja según el enfoque de reponderación representado en el eje horizontal. Al igual que en el caso de la reponderación mediante el espectro, el alquiler de viviendas es el último punto a la derecha, lo cual indica que es el ítem menos volátil de los 292 que conforman el IPC. 


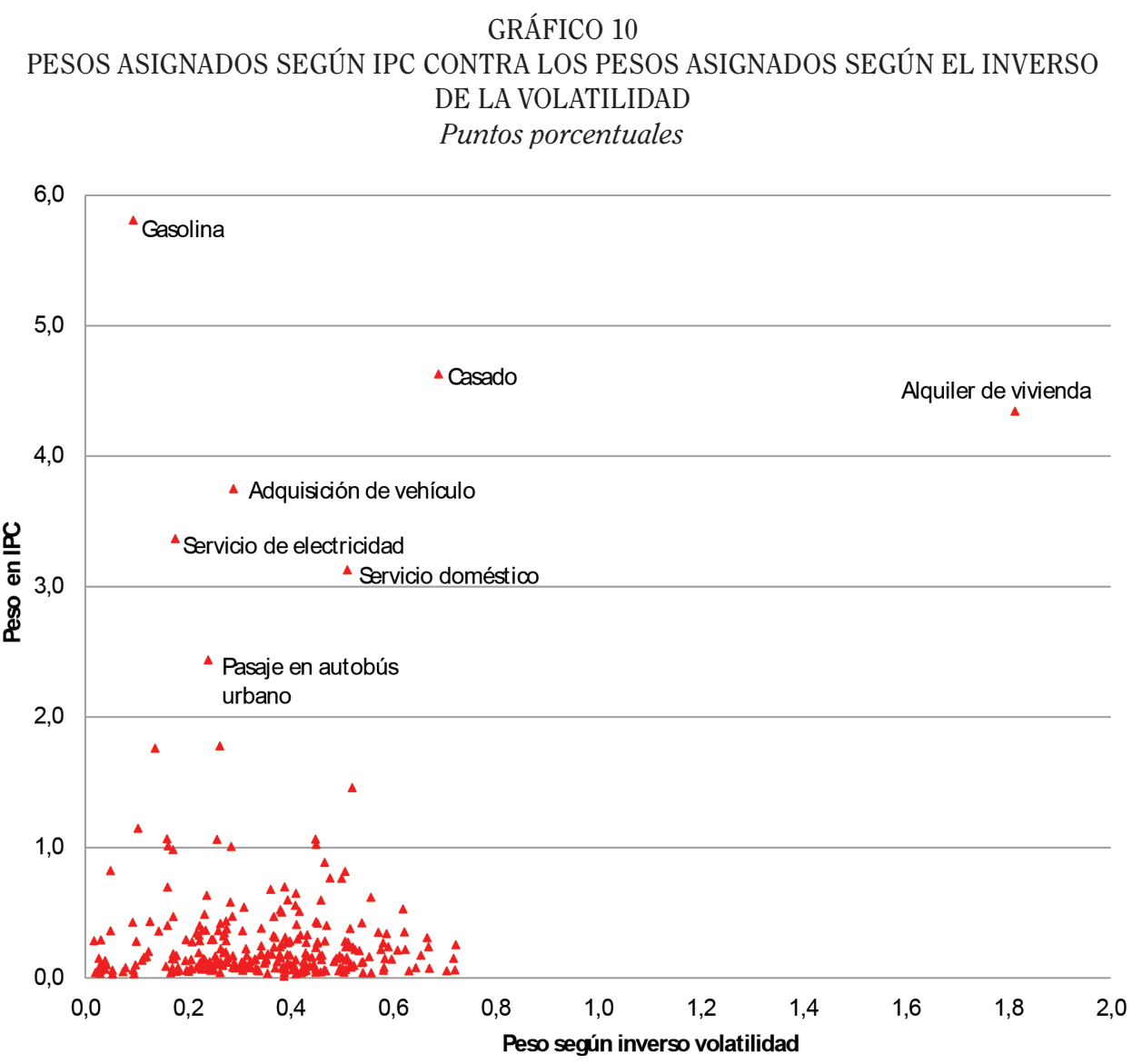

Fuente: elaboración propia.

En particular, si se compara la evolución del índice para gasolina contra el índice para el alquiler de viviendas se puede apreciar la distinción entre medidas de volatilidad versus medidas de persistencia. El gráfico 11 muestra cómo el precio de la gasolina presenta una alta volatilidad pero una baja persistencia, evidencia de que su índice ha cruzado al menos 5 veces, en los últimos 6 años, el valor base 100. Por el contrario, el alquiler de viviendas presenta un comportamiento de baja volatilidad pero siempre creciente. 


\section{GRÁFICO 11 \\ EVOLUCIÓN DEL ÍNDICE PARA LA GASOLINA Y EL ÍNDICE \\ PARA EL ALQUILER DE VIVIENDAS}
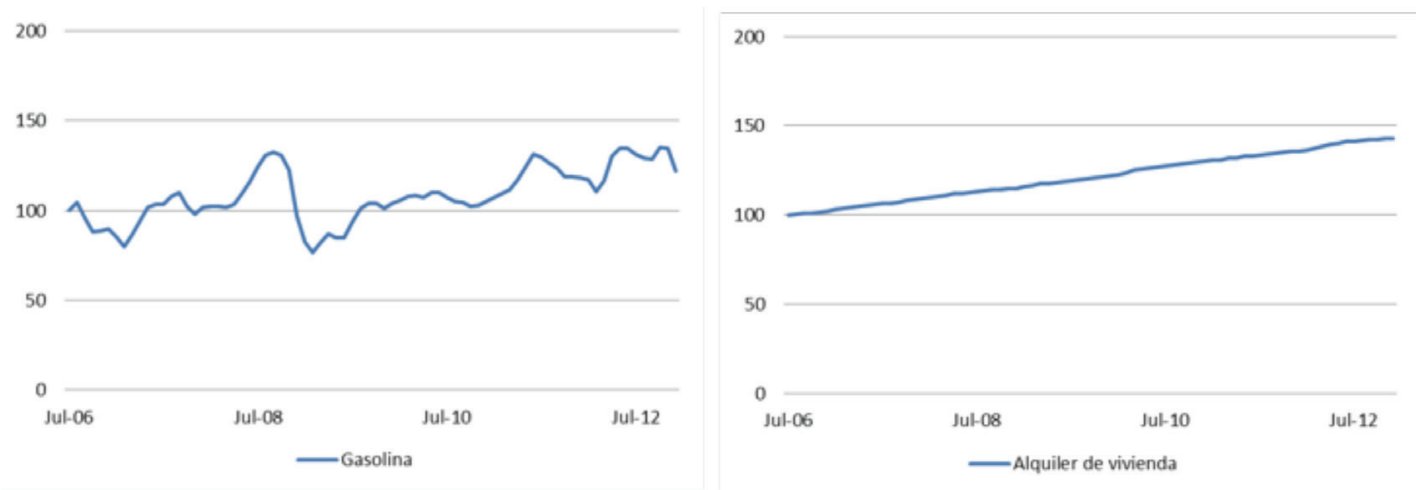

Fuente: elaboración propia.

Finalmente, es importante preguntarse si existe alguna relación entre la persistencia y la volatilidad. El gráfico 12 presenta una comparación entre los pesos asignados por medio de espectro flat $y$ las ponderaciones según el inverso de la volatilidad. En general, se observa que no necesariamente existe una relación entre ambos enfoques.
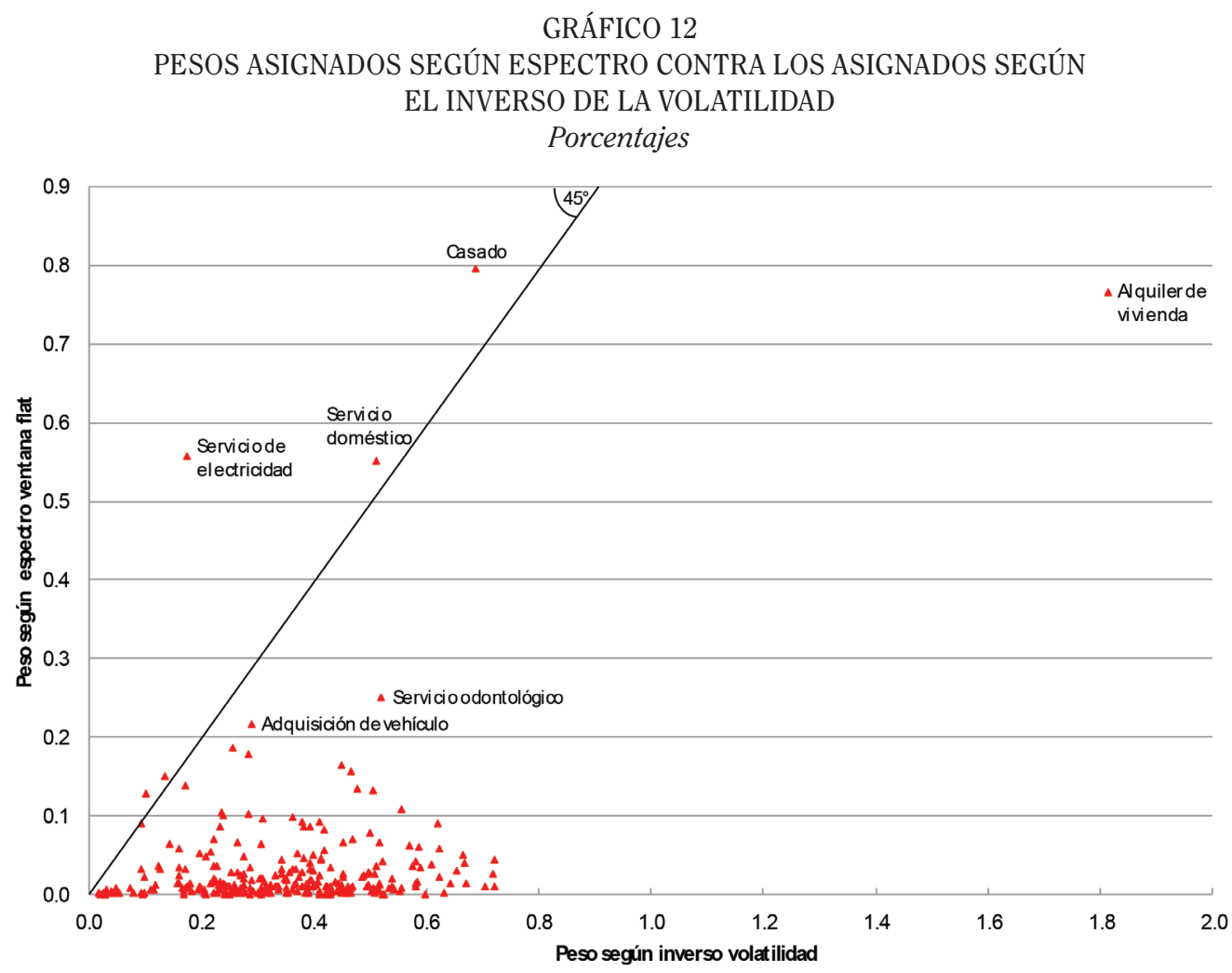

Fuente: elaboración propia. 


\section{EVALUACIÓN DE INDICADORES DE INFLACIÓN SUBYACENTE}

En esta sección se presentan los resultados de la evaluación de algunas propiedades deseables para medidas de inflación subyacente. Dicha valoración tiene dos objetivos: identificar una medida de exclusión con propiedades que superen las de la serie vigente del ISI, e identificar otras medidas de inflación subyacente cuyo seguimiento pueda ser útil para el BCCR.

\section{Prueba de insesgamiento}

Se utilizó el enfoque sugerido por Cogley (2002) para evaluar la propiedad de insesgamiento para medidas de inflación subyacente. Esto equivale a probar que $\alpha_{h}=0$ y $\beta_{h}=1$ y en la siguiente ecuación

$$
\pi_{t+h}-\pi_{t}=\alpha_{h}+\beta_{h}\left(\pi_{t}^{s}-\pi_{t}\right)+u_{t+h}
$$

Esta expresión implica que desviaciones de la inflación subyacente $\pi_{\mathrm{t}}^{\mathrm{s}}$ con respecto a la inflación oficial $\pi_{t}$ deberían estar inversamente relacionadas con cambios subsecuentes en la inflación oficial. La prueba se realiza para horizontes de $\mathrm{h}=1,3,6,12,18$ y 24 meses, usando tasas de variación mensual ${ }^{22}$.

El cuadro 6 muestra los resultados para la prueba de hipótesis conjunta $\alpha_{h}=0$ y $\beta_{h}=1$, a un nivel de significancia de 5\%. Las series se ordenan de acuerdo con el número de veces que la hipótesis nula de insesgamiento no se rechazó, para todos los horizontes considerados. En general, las medidas de exclusión tienen un mejor desempeño en comparación con las medidas de reponderación. Sin embargo, es importante mencionar que la hipótesis nula fue rechazada menos veces para los horizontes de 6 y 12 meses, y que solamente la serie calculada usando la inversa de la desviación estándar con doble ponderación pasó la prueba para el horizonte de 1 mes.

En particular, para cinco series se rechazó la nula de insesgamiento para todos los horizontes. Estas series son variantes de la metodología de coeficientes autorregresivos, la metodología del inverso de la variancia móvil con doble ponderación y la serie calculada usando la correlación con futuras variaciones del IPC. La IMT se localiza a mitad del cuadro, pues la hipótesis nula conjunta se rechazó para horizontes de 1,3, y 24 meses.

Por otra parte, hay 10 series que pasaron la prueba de insesgamiento para 5 horizontes y una de ellas es el ISI vigente. De estas 10 series, 8 son medidas de exclusión: el ISI vigente, 5 indicadores ISI_j y 2 medidas adicionales. Se pueden interpretar estas 10 series como los mejores predictores insesgados de inflación futura. 
CUADRO 6

RESULTADOS DE PRUEBA DE INSESGAMIENTO, RESTRICCIÓN CONJUNTA $\alpha=0$ AND $\beta=1$

\begin{tabular}{|c|c|c|c|c|c|c|c|}
\hline & $1 \mathrm{mes}$ & 3 meses & 6 meses & 12 meses & 18 meses & 24 meses & Total \\
\hline ISI & 0 & 1 & 1 & 1 & 1 & 1 & 5 \\
\hline IPCX & 0 & 1 & 1 & 1 & 1 & 1 & 5 \\
\hline IPCX1 & 0 & 1 & 1 & 1 & 1 & 1 & 5 \\
\hline ISI_41 & 0 & 1 & 1 & 1 & 1 & 1 & 5 \\
\hline ISI_42 & 0 & 1 & 1 & 1 & 1 & 1 & 5 \\
\hline ISI_43 & 0 & 1 & 1 & 1 & 1 & 1 & 5 \\
\hline ISI_44 & 0 & 1 & 1 & 1 & 1 & 1 & 5 \\
\hline ISI_45 & 0 & 1 & 1 & 1 & 1 & 1 & 5 \\
\hline R_1_inversa_volat & 0 & 1 & 1 & 1 & 1 & 1 & 5 \\
\hline R_2_inversa_volat & 1 & 0 & 1 & 1 & 1 & 1 & 5 \\
\hline IPCX2 & 0 & 1 & 0 & 1 & 1 & 1 & 4 \\
\hline ISI_46 & 0 & 1 & 1 & 1 & 1 & 0 & 4 \\
\hline ISI_47 & 0 & 1 & 1 & 1 & 1 & 0 & 4 \\
\hline ISI_48 & 0 & 1 & 1 & 1 & 1 & 0 & 4 \\
\hline ISI_49 & 0 & 1 & 1 & 1 & 1 & 0 & 4 \\
\hline ISI_50 & 0 & 1 & 1 & 1 & 1 & 0 & 4 \\
\hline ISI_51 & 0 & 1 & 1 & 1 & 1 & 0 & 4 \\
\hline R_2_espect_flat & 0 & 1 & 1 & 1 & 0 & 1 & 4 \\
\hline IMT & 0 & 0 & 1 & 1 & 1 & 0 & 3 \\
\hline IPCX3 & 0 & 1 & 0 & 1 & 1 & 0 & 3 \\
\hline R_2_espect_comb & 0 & 0 & 1 & 1 & 0 & 1 & 3 \\
\hline R_2_espect_quad & 0 & 0 & 1 & 1 & 0 & 1 & 3 \\
\hline R_2_espect_tent & 0 & 0 & 1 & 1 & 0 & 1 & 3 \\
\hline R_1_var_movil24 & 0 & 0 & 0 & 1 & 0 & 1 & 2 \\
\hline R_1_var_movil36 & 0 & 0 & 0 & 0 & 1 & 1 & 2 \\
\hline R_2_cruce_medias & 0 & 1 & 0 & 0 & 0 & 0 & 1 \\
\hline R_2_var_movil36 & 0 & 1 & 0 & 0 & 0 & 0 & 1 \\
\hline R_1_AR & 0 & 0 & 0 & 0 & 0 & 0 & 0 \\
\hline R_2_AR & 0 & 0 & 0 & 0 & 0 & 0 & 0 \\
\hline R_1_var_futura & 0 & 0 & 0 & 0 & 0 & 0 & 0 \\
\hline R_1_AR1 & 0 & 0 & 0 & 0 & 0 & 0 & 0 \\
\hline R_2_var_movil24 & 0 & 0 & 0 & 0 & 0 & 0 & 0 \\
\hline
\end{tabular}

Nota: 1 indica no rechazo de la nula de insesgamiento.

Fuente: elaboración propia. 
A fin de evaluar cuán cerca están los coeficientes estimados de los valores ideales en caso de insesgamiento, el cuadro 7 presenta un ordenamiento de los indicadores con base en la suma de las desviaciones cuadradas con respecto a los valores de la hipótesis nula $\alpha=0$ y $\beta=1$. Las desviaciones se calcularon con base en los coeficientes de la regresión de Cogley para horizontes $\mathrm{de} h=1$, 3, 6, 12, 18 y 24 meses. En general, la IMT tiene las menores desviaciones para horizontes de 1 y 6 meses, mientras que el ISI vigente se ubica entre las 10 primeras posiciones para todos los horizontes. Sin embargo, algunos de los nuevos indicadores de exclusión propuestos tienen mejores resultados para 3, 6, 12 y 18 meses. Además, la serie ISI_41 se ubica en primer y segundo lugar para 3 y 12 meses, y la ISI_46 (la de mejor ajuste con la tendencia de inflación) aparece en 3 de los 6 horizontes de tiempo.

Para dar una idea del desempeño relativo de las medidas ISI_j de exclusión por volatilidad propuestas, el cuadro 8 presenta un ordenamiento considerando exclusivamente estas series. El primer lugar de cada horizonte corresponde alternativamente al ISI vigente ( 1 y 24 meses), la serie ISI_41 (3 y 12 meses) y la serie ISI_51 (6 y 18 meses). Los peores resultados, considerando las últimas tres posiciones, corresponden al ISI_51, el ISI_49 y el ISI_50. Es destacable el desempeño irregular del ISI_51, encabezando algunos ordenamientos y cerrando otros. 


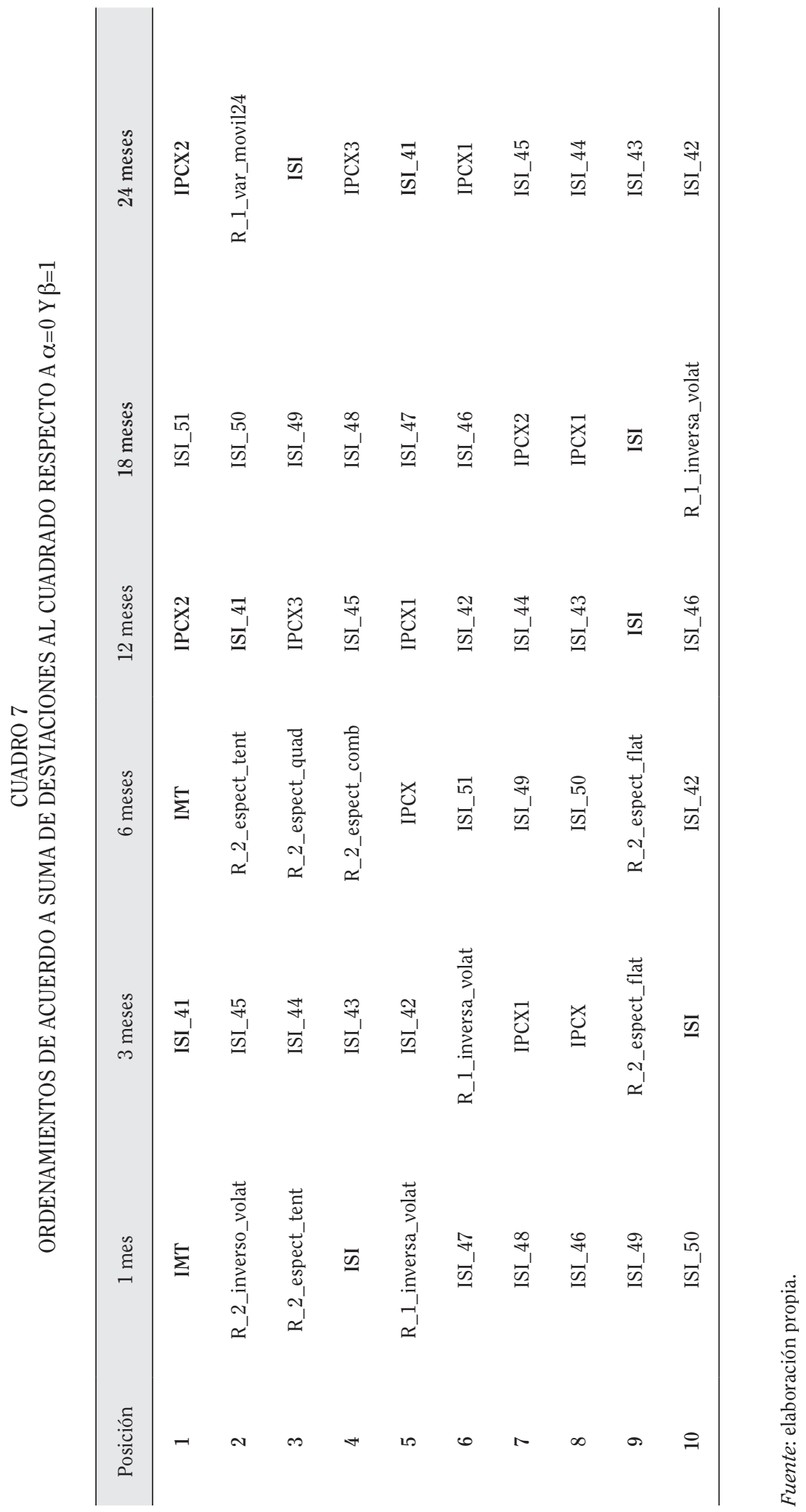




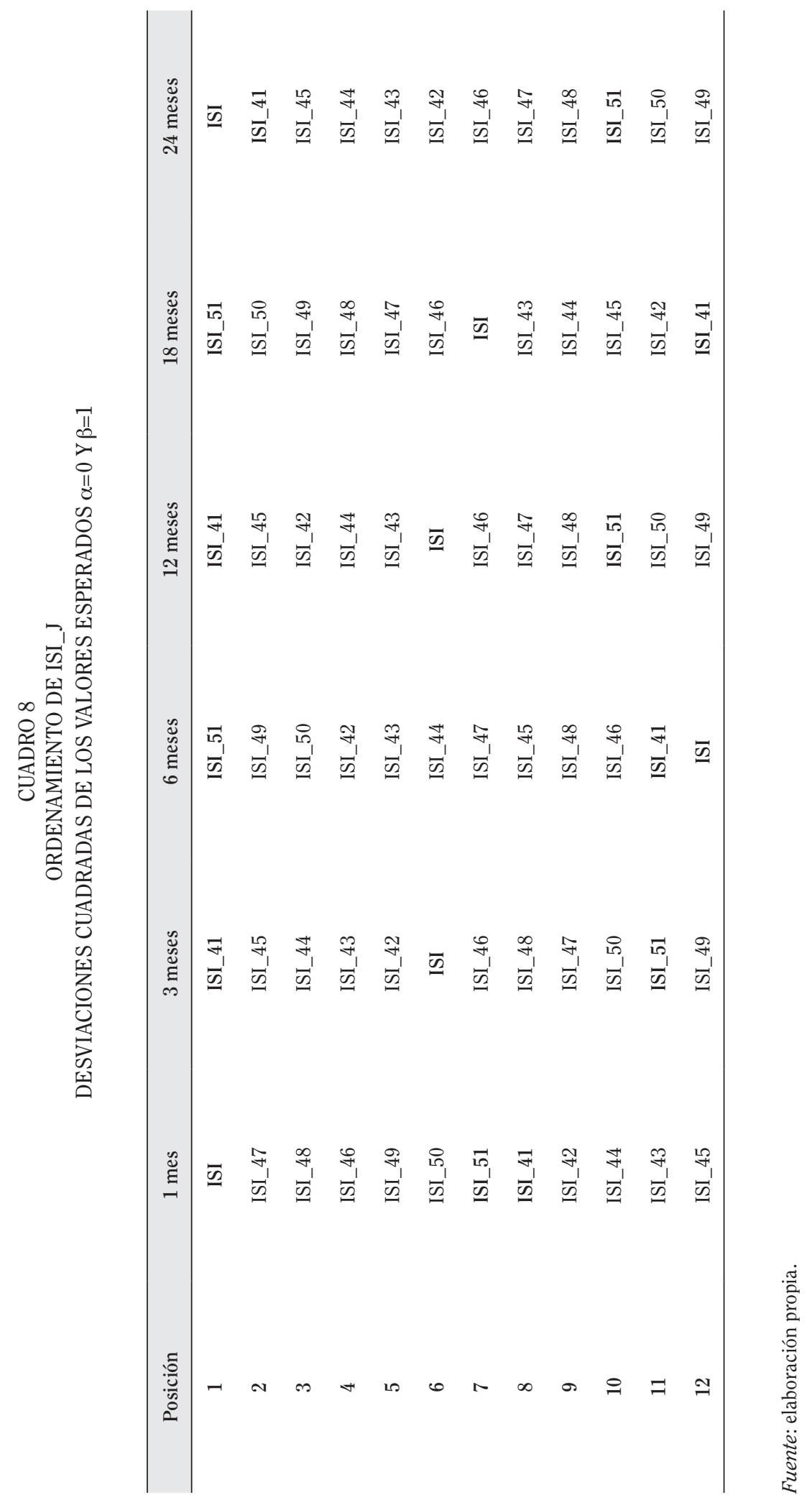




\section{2. $\quad$ Ajuste a tendencia de inflación}

Otro criterio usual para la evaluación de medidas de inflación subyacente es su ajuste a un indicador de tendencia de la inflación. Para este propósito, se usa la media móvil de 24 meses como el indicador a partir del cual calcular la raíz del error cuadrático medio (RECM) y la desviación absoluta media (DAM) para todas las medidas de inflación subyacente ${ }^{23}$. El cuadro 9 muestra los resultados.

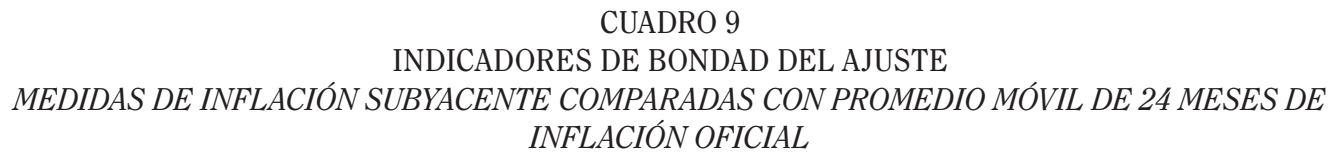

\begin{tabular}{|c|c|c|c|}
\hline & RECM & & DAM \\
\hline R_1_var movil36* & 0,27 & IMT & 0,19 \\
\hline R_2_inversa_volat & 0,27 & R_2_inversa_volat & 0,20 \\
\hline R_1_inversa_volat & 0,29 & R_2_var_movil36* & 0,20 \\
\hline IMT & 0,29 & ISI_51 & 0,21 \\
\hline ISI_51 & 0,29 & ISI_50 & 0,21 \\
\hline ISI_49 & 0,29 & ISI_49 & 0,21 \\
\hline ISI_50 & 0,29 & ISI_48 & 0,21 \\
\hline ISI_48 & 0,30 & ISI_47 & 0,21 \\
\hline ISI_47 & 0,30 & ISI_46 & 0,21 \\
\hline ISI_46 & 0,30 & R_1_inversa_volat & 0,22 \\
\hline ISI_42 & 0,32 & R_1_var_movil36* & 0,23 \\
\hline ISI_43 & 0,32 & ISI_45 & 0,24 \\
\hline ISI_44 & 0,32 & ISI_44 & 0,24 \\
\hline ISI_45 & 0,32 & ISI_42 & 0,24 \\
\hline ISI_41 & 0,32 & ISI_43 & 0,24 \\
\hline IPCX1 & 0,33 & ISI_41 & 0,24 \\
\hline R_2_var_movil36* & 0,33 & IPCX1 & 0,26 \\
\hline ISI & 0,35 & IPCX & 0,27 \\
\hline IPCX & 0,35 & R_2_espect_flat & 0,27 \\
\hline IPCX2 & 0,36 & R_2_espect_tent & 0,27 \\
\hline R_2_espect_tent & 0,37 & R_2_espect_comb & 0,27 \\
\hline R_2_espect_comb & 0,38 & R_2_espect_quad & 0,27 \\
\hline R_2_espect_flat & 0,38 & ISI & 0,28 \\
\hline R_2_espect_quad & 0,38 & IPCX2 & 0,30 \\
\hline R_1_var_movil24* & 0,39 & IPCX3 & 0,31 \\
\hline IPCX3 & 0,40 & R_1_var_movil24* & 0,32 \\
\hline IPC & 0,47 & R_2_var_movil24* & 0,34 \\
\hline R_2_var_movil24* & 0,51 & IPC & 0,36 \\
\hline R_2_cruce_medias* & 0,51 & R_2_cruce_medias* & 0,39 \\
\hline R_1_var_futura* & 0,74 & R_1_var_futura* & 0,60 \\
\hline R_1_AR1* & 1,26 & R_1_AR1* & 1,01 \\
\hline R_2_AR* & 1,80 & R_2_AR* & 1,12 \\
\hline R_1_AR* & 2,03 & R_1_AR* & 1,16 \\
\hline
\end{tabular}

(*) No pasó prueba de insesgamiento para 3 horizontes o más.

Fuente: elaboración propia

23 La escogencia de este indicador se basó en Esquivel, Rodríguez y Vásquez (2011), quienes evaluaron promedios móviles de 24 y 36 meses de la inflación oficial y encontraron que la de 24 meses es una medida insesgada de la inflación oficial futura. 
Las series con el mejor ajuste incluyen a la IMT y a medidas de reponderación. Dos de estas (inversa de desviación estándar y de la variancia móvil de 36 meses), se calcularon tomando en cuenta tanto el peso original de cada producto como el ajuste a la ponderación propuesto (metodología de doble ponderación). En general, los métodos de doble ponderación se desempeñan mejor que los métodos correspondientes que ignoran la composición original de la canasta de consumo.

Dentro de los indicadores basados en exclusión, todas las ISI propuestas muestran menores medidas de error en comparación con el ISI vigente. Este resultado valida las observaciones preliminares sobre su pobre desempeño para aproximar la tendencia de la inflación.

Al igual que en las pruebas de insesgamiento, las series calculadas con el método de los coeficientes autorregresivos mostraron el peor desempeño. Las medidas de exclusión IPCX2, IPCX3 e IPCX se encuentran también entre las de peor ajuste.

\section{Predicción de la dirección de cambios en la inflación oficial}

Usando la ecuación propuesta por Cogley (2002), se estima pronósticos móviles (rolling forecasts) para horizontes de $\mathrm{h}=1,3,6$ y 12 meses hacia adelante, con el fin de predecir la dirección de los cambios en la inflación oficial entre las fechas $t$ y $t+h$ usando para ello la brecha observada en el periodo t entre la inflación oficial y la subyacente. Este ejercicio se realiza solamente para 28 series, excluyendo las versiones de variancia móvil debido a su reducido número de observaciones ${ }^{24}$.

El cuadro 10 presenta los primeros 12 lugares de un ordenamiento hecho con base en el porcentaje de acierto de las direcciones de los cambios. En general, todos los porcentajes de acierto están por encima del $50 \%$.

Considerando las medidas vigentes de inflación subyacente, la IMT se ubica dentro de los 6 primeros lugares para todos los horizontes. En contraste, el ISI está excluido de los 12 primeros lugares para los horizontes de 3 y 12 meses, aun así, mostró buena capacidad predictiva para horizontes de 1 mes y 6 meses. Entre las medidas ISI alternativas, la serie ISI_41 mostró un buen desempeño para todos los horizontes.

Las medidas de reponderación basadas en el espectro mostraron buen poder predictivo. En particular, mostraron mayor precisión para pronósticos de corto plazo, de 1 y 3 meses, compartiendo el segundo y primer lugar, respectivamente. Además, la medida basada en el inverso de la desviación estándar tuvo de nuevo un buen desempeño, con el porcentaje de acierto más alto para los horizontes de 1 mes y 3 meses. 


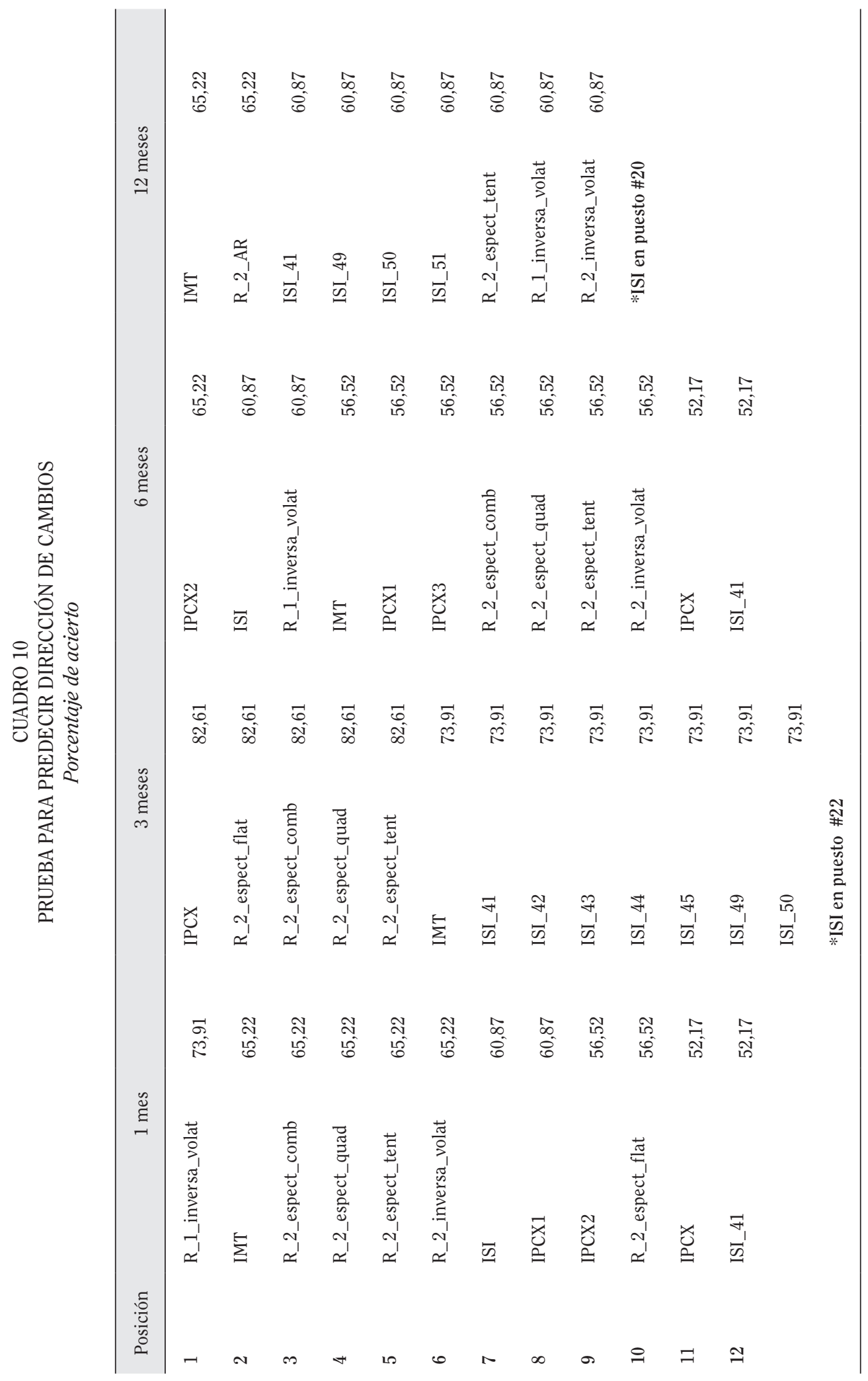


A fin de dar una idea general de capacidad predictiva, el cuadro 11 muestra un ordenamiento general considerando el número total de cambios cuya dirección fue correctamente predicha, agregando para todos los horizontes. Los primeros lugares son medidas de reponderación y la IMT. El ISI vigente se ubica en noveno lugar.

\begin{tabular}{clc} 
CUADRO 11 \\
CAPACIDAD PARA PREDECIR DIRECCIÓN DE CAMBIOS EN INFLACIÓN \\
\multicolumn{3}{c}{ ORDENAMIENTO GENERAL } \\
Porcentaje de acierto \\
\hline \multicolumn{3}{c}{ Serie } \\
\hline Posición & \multicolumn{1}{c}{ Porcentaje de acierto } \\
\hline 1 & R_2_espect_tent & 66,30 \\
2 & R_1_inversa_volat & 66,30 \\
3 & IMT & 65,22 \\
4 & R_2_espect_quad & 65,22 \\
5 & R_2_espect_comb & 64,13 \\
6 & R_2_inversa_volat & 61,96 \\
7 & ISI_41 & 59,78 \\
8 & R_1_espect_flat & 59,78 \\
9 & ISI & 58,70 \\
10 & IPCX & 58,70 \\
& IPCX1 & 58,70 \\
& ISI_49 & 58,70 \\
& ISI_50 & 58,70 \\
\hline
\end{tabular}

Fuente: elaboración propia.

\section{Pruebas de capacidad predictiva}

Usamos la prueba de Diebold y Mariano (1995) para comparar la capacidad predictiva de cada posible par de pronósticos calculados usando la especificación de Cogley discutida en la sección 4.1. El cuadro 12 presenta el número de pruebas en las cuales la nula de igual capacidad de pronóstico es rechazada en favor de mayor exactitud para la serie listada en el cuadro, para todos los horizontes de pronósticos $(\mathrm{h}=1,3,6,12,24)$. El IMT es el indicador que presenta mayor número de rechazos de la nula en su favor. En general, las medidas de exclusión tienen mayor capacidad predictiva que las medidas de reponderación. Hay 7 medidas de exclusión entre los primeros 10 lugares. Aun así, el segundo y tercer lugar corresponden a medidas de reponderación. De esas 7, 6 son indicadores ISI_j, entre ellos la ISI_48 y la ISI_46. Sin embargo, la serie ISI_41, que ha mostrado un buen desempeño en otras pruebas, se ubica en el puesto 16. 
CUADRO 12

PRUEBA DE DIEBOLD-MARIANO PARA COMPARAR CAPACIDAD PREDICTIVA

\begin{tabular}{|c|c|c|c|}
\hline & Serie & $\begin{array}{l}\text { Rechazos de la hipótesis nula de } \\
\text { igual capacidad de pronóstico }\end{array}$ & $\begin{array}{c}\text { Porcentaje del total de } \\
\text { pruebas }\end{array}$ \\
\hline 1 & IMT & 34 & $31,48 \%$ \\
\hline 2 & R_1_inversa_volat & 30 & $27,78 \%$ \\
\hline 3 & R_2_inversa_volat & 29 & $26,85 \%$ \\
\hline 4 & ISI_48 & 19 & $17,59 \%$ \\
\hline 5 & ISI_46 & 18 & $16,67 \%$ \\
\hline 6 & ISI_47 & 18 & $16,67 \%$ \\
\hline 7 & ISI_49 & 18 & $16,67 \%$ \\
\hline 8 & ISI_50 & 18 & $16,67 \%$ \\
\hline 9 & ISI_51 & 18 & $16,67 \%$ \\
\hline 10 & ISI & 16 & $14,81 \%$ \\
\hline 11 & IPCX1 & 13 & $12,04 \%$ \\
\hline 12 & ISI_44 & 12 & $11,11 \%$ \\
\hline 13 & ISI_45 & 11 & $10,19 \%$ \\
\hline 14 & ISI_42 & 10 & $9,26 \%$ \\
\hline 15 & ISI_43 & 10 & $9,26 \%$ \\
\hline 16 & ISI_41 & 9 & $8,33 \%$ \\
\hline 17 & IPCX & 7 & $6,48 \%$ \\
\hline 18 & IPCX2 & 7 & $6,48 \%$ \\
\hline 19 & R_2_cruce_medias* & 7 & $6,48 \%$ \\
\hline 20 & IPCX3 & 6 & $5,56 \%$ \\
\hline 21 & R_2_espect_quad & 6 & $5,56 \%$ \\
\hline 22 & R_2_espect_flat & 5 & $4,63 \%$ \\
\hline 23 & R_2_espect_comb & 5 & $4,63 \%$ \\
\hline 24 & R_2_espect_tent & 5 & $4,63 \%$ \\
\hline 25 & R_2_AR* & 2 & $1,85 \%$ \\
\hline 26 & R_1_AR* & 1 & $0,93 \%$ \\
\hline 27 & R_1_var_futura* & 1 & $0,93 \%$ \\
\hline 28 & R_1_AR1* & 1 & $0,93 \%$ \\
\hline
\end{tabular}

(*) No pasó prueba de insesgamiento para 3 horizontes o más.

Fuente: elaboración propia. 


\section{Evaluación mediante SVAR para propiedades de largo plazo}

El objetivo de los indicadores de inflación subyacente es señalar movimientos de mediano y largo plazo en la inflación, asociados con presiones de demanda. Por ende, no deberían mostrar efectos duraderos ante choques transitorios en los precios. Lahura y Vega (2011) sugieren una metodología basada en VAR estructurales (SVAR) para evaluar las propiedades de largo plazo de tales indicadores. Bajo los supuestos de que el índice de precios es no estacionario, y que tanto la inflación oficial $\pi_{t}$ como la subyacente $\pi_{\mathrm{t}}^{\mathrm{s}}$ son estacionarias, la representación vectorial de medias móviles de $\pi_{t} y \pi_{\mathrm{t}}^{\mathrm{s}}$ está dada por

$$
\left[\begin{array}{l}
\pi_{t} \\
\pi_{t}^{s}
\end{array}\right]=\left[\begin{array}{l}
\bar{\pi} \\
\bar{\pi}^{s}
\end{array}\right]+\sum_{i=0}^{\infty}\left[\begin{array}{ll}
\phi_{11}(i) & \phi_{12}(i) \\
\phi_{21}(i) & \phi_{22}(i)
\end{array}\right]\left[\begin{array}{c}
\varepsilon_{t-i}^{T} \\
\varepsilon_{t-i}^{P}
\end{array}\right]
$$

donde las innovaciones fundamentales $\varepsilon_{t}^{T} y \varepsilon_{h}^{P}$ son, respectivamente, una perturbación transitoria y una perturbación permanente. Puesto que ambas medidas de inflación son estacionarias, ninguno de los choques debería tener efectos de largo plazo sobre ellas. Por otra parte, dado que el nivel de precios es no estacionario, ambas perturbaciones deberían tener efectos de largo plazo en él. Los autores proponen una estrategia de identificación basada en una restricción de largo plazo, siguiendo a Blanchard $y$ Quah (1989). Suponen que $\sum_{i=0}^{\infty} \emptyset_{11}(i)=0$, lo cual implica que la perturbación transitoria $\varepsilon_{t}^{T}$ no tiene efecto de largo plazo sobre el índice de precios. Este esquema de identificación permite el uso de funciones de impulso-respuesta (FIR) y de descomposiciones de variancia (DV) para evaluar la medida en que los indicadores de inflación subyacente se ven afectados en el largo plazo por choques transitorios. Una medida de inflación subyacente con propiedades de largo plazo deseables requiere que su respuesta acumulada a $\varepsilon_{t}^{T}$ sea pequeña, y que sólo una parte reducida de su variancia se deba a tales choques transitorios. Esto implica comparar entre indicadores el tamaño de $\sum_{i=0}^{\infty} \emptyset_{21}(i)$ el porcentaje de la variancia explicada por $\varepsilon_{t^{T}}^{T}$

Se estima 32 VAR, cada uno incluyendo la inflación oficial y una de las medidas de inflación subyacente presentadas en la sección $3, y$ a partir de la forma identificada del VAR se obtuvieron descomposiciones de variancia y FIR para el choque $\varepsilon_{t}^{T 25}$. El cuadro 13 presenta estimaciones del valor de $\sum_{i=0}^{\infty} \emptyset_{21}(i)$ para cada sistema, medido como la respuesta acumulada en el período $100^{26}$.

25 De acuerdo con el criterio de información de Schwarz, debería escogerse una amplitud de rezago de $l=1$ en 27 de los 32 casos. Sin embargo, el Hannan-Quinn sugiere $l=2$ en 18 casos y el Akaike $l>2$ en todos los casos. En vista de esto se escogió un largo de 2 rezagos. 
CUADRO 13

RESPUESTA ACUMULADA A UN CHOQUE TRANSITORIO DESPUÉS DE 100 MESES Puntos porcentuales

\begin{tabular}{|c|c|c|c|c|c|}
\hline \multicolumn{5}{|c|}{ Respuesta acumulada } & \multirow{2}{*}{$\frac{\text { Respuesta acumulada }}{0,368}$} \\
\hline 1 & R_2_cruce_medias & 0,130 & 17 & IPCX1 & \\
\hline 2 & R_1_var_movil36 & 0,186 & 18 & R_2_espect_comb & 0,369 \\
\hline 3 & R_2_inversa_volat & 0,192 & 19 & R_2_espect_quad & 0,373 \\
\hline 4 & ISI_47 & 0,264 & 20 & ISI_44 & 0,375 \\
\hline 5 & ISI_48 & 0,264 & 21 & ISI_45 & 0,375 \\
\hline 6 & ISI_46 & 0,268 & 22 & R_2_espect_flat & 0,375 \\
\hline 7 & ISI_51 & 0,272 & 23 & ISI_42 & 0,376 \\
\hline 8 & ISI_49 & 0,272 & 24 & ISI_43 & 0,377 \\
\hline 9 & ISI_50 & 0,273 & 25 & IPCX3 & 0,377 \\
\hline 10 & R_2_var_movil36 & 0,278 & 26 & ISI_41 & 0,390 \\
\hline 11 & R_1_inversa_volat & 0,283 & 27 & R_1_var_movil24 & 0,450 \\
\hline 12 & IMT & 0,290 & 28 & R_2_var_movil24 & 0,459 \\
\hline 13 & IPCX & 0,313 & 29 & R_1_var_futura & 0,585 \\
\hline 14 & ISI & 0,315 & 30 & R_1_AR & 1,304 \\
\hline 15 & R_2_espect_tent & 0,347 & 31 & $\mathrm{R} \_2 \_A R$ & 1,311 \\
\hline 16 & IPCX2 & 0,366 & 32 & R_1_AR1 & 1,405 \\
\hline
\end{tabular}

Fuente: elaboración propia.

Las medidas de reponderación presentan las respuestas de largo plazo más bajas a los choques transitorios. En particular, los indicadores calculados usando inversas de la volatilidad (inversa de la desviación estándar y variancia móvil de 36 meses) vuelven a mostrar el mejor comportamiento, como en la evaluación del ajuste a la tendencia. Sin embargo, el indicador con la respuesta más baja es el calculado con el inverso del número de cruces de la media como indicador de persistencia, que no ha mostrado un buen desempeño en las secciones previas. Los indicadores con las respuestas más grandes a choques transitorios son todos medidas de reponderación basados en coeficientes autorregresivos.

El cuadro 14 muestra el porcentaje de la variancia de cada indicador de inflación subyacente que es explicado por el choque transitorio a varios horizontes. Después de 100 meses, entre los indicadores con los menores porcentajes de variancia están los basados en estimaciones del espectro (menos del 8\% de la variancia explicada por el choque transitorio), el indicador basado en el número de cruces de la media y la IMT (alrededor de 7\%), así como los indicadores ponderados con el inverso de su volatilidad. Debe notarse que aunque el ISI vigente es la medida de exclusión que muestra propiedades de largo plazo más adecuadas, el porcentaje de su variancia atribuible a choques transitorios es casi el doble del de la IMT. Todas las medidas ISI propuestas se ubican en las posiciones intermedias, con porcentajes entre $13 \%$ y $20 \%$ de la variancia ${ }^{27}$. Por otro parte, las variancias de los indicadores calculados a partir de coeficientes autorregresivos y variancias móviles se ven fuertemente influenciadas a largo plazo por choques transitorios (todos los porcentajes por encima del $50 \%$ ).

27 Las descomposiciones de variancia realizadas por Lahura y Vega (2011) para varias medidas de exclusión para Perú resultan en un rango más reducido, $9,3 \%$ a 15,1\%, con la medida oficial de inflación subyacente en $10 \%$. 
CUADRO 14

DESCOMPOSICIONES DE VARIANCIA ANTE CHOQUES TRANSITORIOS

PORCENTAJE DE LA VARIANCIA EXPLICADA POR EL CHOQUE

\begin{tabular}{|c|c|c|c|c|c|c|c|c|c|}
\hline & & \multicolumn{8}{|c|}{ Mes } \\
\hline & & 1 & 3 & 6 & 12 & 24 & 36 & 72 & 100 \\
\hline 1 & R_2_espect_tent & 2,84 & 4,61 & 5,54 & 5,73 & 5,74 & 5,74 & 5,74 & 5,74 \\
\hline 2 & R_2_espect_comb & 4,70 & 5,99 & 6,76 & 6,92 & 6,92 & 6,92 & 6,92 & 6,92 \\
\hline 3 & IMT & 5,93 & 6,83 & 6,93 & 6,96 & 6,96 & 6,96 & 6,96 & 6,96 \\
\hline 4 & R_2_cruce_medias & 8,94 & 7,10 & 7,07 & 7,07 & 7,07 & 7,07 & 7,07 & 7,07 \\
\hline 5 & R_2_espect_quad & 5,25 & 6,35 & 7,07 & 7,21 & 7,22 & 7,22 & 7,22 & 7,22 \\
\hline 6 & R_1_inverso_volat & 16,34 & 10,31 & 8,57 & 8,07 & 8,01 & 8,01 & 8,01 & 8,01 \\
\hline 7 & R_2_espect_flat & 6,99 & 7,49 & 7,97 & 8,05 & 8,05 & 8,05 & 8,05 & 8,05 \\
\hline 8 & R_2_inversa_volat & 18,84 & 13,70 & 12,46 & 12,33 & 12,33 & 12,33 & 12,33 & 12,33 \\
\hline 9 & ISI & 16,94 & 14,44 & 13,18 & 13,01 & 13,01 & 13,01 & 13,01 & 13,01 \\
\hline 10 & ISI_47 & 22,50 & 15,86 & 13,91 & 13,52 & 13,50 & 13,50 & 13,50 & 13,50 \\
\hline 11 & ISI_48 & 22,69 & 15,97 & 14,01 & 13,62 & 13,60 & 13,60 & 13,60 & 13,60 \\
\hline 12 & ISI_46 & 22,71 & 16,06 & 14,07 & 13,67 & 13,65 & 13,65 & 13,65 & 13,65 \\
\hline 13 & ISI_49 & 23,74 & 17,88 & 15,82 & 15,50 & 15,49 & 15,49 & 15,49 & 15,49 \\
\hline 14 & ISI_50 & 23,97 & 18,03 & 15,96 & 15,63 & 15,62 & 15,62 & 15,62 & 15,62 \\
\hline 15 & ISI_51 & 24,23 & 18,19 & 16,09 & 15,77 & 15,76 & 15,76 & 15,76 & 15,76 \\
\hline 16 & IPCX & 19,08 & 16,71 & 16,47 & 16,45 & 16,45 & 16,45 & 16,45 & 16,45 \\
\hline 17 & ISI_42 & 24,75 & 20,74 & 19,24 & 18,99 & 18,98 & 18,98 & 18,98 & 18,98 \\
\hline 18 & ISI_43 & 25,16 & 21,14 & 19,62 & 19,38 & 19,37 & 19,37 & 19,37 & 19,37 \\
\hline 19 & ISI_44 & 25,43 & 21,39 & 19,84 & 19,60 & 19,59 & 19,59 & 19,59 & 19,59 \\
\hline 20 & ISI_41 & 25,11 & 21,88 & 20,12 & 19,87 & 19,86 & 19,86 & 19,86 & 19,86 \\
\hline 21 & ISI_45 & 26,11 & 21,87 & 20,26 & 20,01 & 20,00 & 20,00 & 20,00 & 20,00 \\
\hline 22 & IPCX1 & 31,15 & 27,19 & 25,20 & 25,06 & 25,06 & 25,06 & 25,06 & 25,06 \\
\hline 23 & IPCX2 & 62,79 & 54,21 & 50,83 & 50,81 & 50,81 & 50,81 & 50,81 & 50,81 \\
\hline 24 & IPCX3 & 57,54 & 53,30 & 52,36 & 52,36 & 52,36 & 52,36 & 52,36 & 52,36 \\
\hline 25 & R_1_var_futura & 81,62 & 55,59 & 55,57 & 55,57 & 55,57 & 55,57 & 55,57 & 55,57 \\
\hline 26 & R_2_AR & 69,53 & 65,36 & 65,05 & 65,05 & 65,05 & 65,05 & 65,05 & 65,05 \\
\hline 27 & R_2_var_movil36 & 99,15 & 74,79 & 71,12 & 70,63 & 70,63 & 70,63 & 70,63 & 70,63 \\
\hline 28 & R_1_AR1 & 94,33 & 79,05 & 76,78 & 76,77 & 76,77 & 76,77 & 76,77 & 76,77 \\
\hline 29 & R_1_var_movil36 & 89,51 & 80,82 & 77,15 & 76,82 & 76,81 & 76,81 & 76,81 & 76,81 \\
\hline 30 & R_1_var_movil24 & 93,70 & 90,68 & 90,61 & 90,61 & 90,61 & 90,61 & 90,61 & 90,61 \\
\hline 31 & R_2_var_movil24 & 98,27 & 92,29 & 91,86 & 91,84 & 91,84 & 91,84 & 91,84 & 91,84 \\
\hline 32 & R_1_AR & 98,12 & 94,41 & 92,85 & 92,83 & 92,83 & 92,83 & 92,83 & 92,83 \\
\hline
\end{tabular}

Fuente: elaboración propia. 


\section{6. $\quad$ Selección de indicadores}

La evaluación realizada en las secciones 4.1 a 4.5 permite elegir indicadores de inflación subyacente con propiedades deseables a los cuales darles seguimiento. En esta selección se le asigna particular importancia al insesgamiento del indicador y a su capacidad de pronóstico de la serie de inflación IPC.

De los indicadores de exclusión por volatilidad, los ISI_j, se encontró que el ISI_41, el ISI_42, el ISI_43, el ISI_44 y el ISI_45 tienen las mismas propiedades de insesgamiento que el ISI vigente, como se puede apreciar en el cuadro 6. No obstante, las otras series ISI también se encuentran muy bien posicionadas. De estos indicadores, el ISI_41 y el ISI_45 aparecen dentro de los primeros 5 lugares de las 32 series evaluadas en el ordenamiento de acuerdo a la suma de desviaciones al cuadrado de los coeficientes de la prueba de insesgamiento (cuadro 7). Asimismo, considerando sólo las series ISI, el ISI 46 aparece 5 veces dentro de las primeras 7 posiciones (cuadro 8), mientras que el peor desempeño fue del ISI_49, que se ubicó tres veces en el último lugar. Con respecto a la bondad del ajuste, las 10 series presentan resultados similares, todas ubicadas por encima del ISI vigente.

En términos de la capacidad predictiva de la dirección de los cambios, el ISI_41 se ubica dentro de las primeras 10 posiciones en todos los horizontes considerados, mientras que las otras medidas aparecen en un máximo de dos horizontes. Por otro lado, en la prueba Diebold -Mariano de capacidad predictiva, las series entre ISI_46 e ISI_51 son las mejor ubicadas, con el ISI_41 en el último lugar de este tipo de indicadores de exclusión.

Finalmente, el ISI_46, ISI_47 e ISI_48 son los que presentan los mejores resultados en las pruebas para propiedades de largo plazo, ubicándose el ISI_41 en penúltimo lugar de las series ISI, sólo por encima de la ISI_45.

Así, se concluye que los indicadores ISI en general se pueden considerar insesgados para la mayoría de horizontes. Asimismo, buscando un balance entre estas propiedades y las de largo plazo, $y$ dando prioridad también a la capacidad predictiva por medio de la prueba de Diebold - Mariano se tiene 2 posibles indicadores de exclusión por volatilidad: el ISI _41 y el ISI_46. El ISI_41 fue consistentemente superior en la suma de desviaciones al cuadrado de los coeficientes asociados a las pruebas de insesgamiento y presentó mayor capacidad predictiva en la dirección de los cambios. Por otro lado, el ISI_46 se posiciona mejor en la prueba de Diebold-Mariano, se ubica en el segundo lugar de las ISI para las pruebas de largo plazo y es marginalmente mejor en las pruebas complementarias de insesgamiento que el ISI_47 y el ISI_48, que presentan propiedades similares al ISI_46.

Así, procurando un balance entre todas las propiedades y considerando la relevancia del comportamiento de estos indicadores en el largo plazo y la capacidad predictiva, se selecciona la ISI_46 como reemplazo del ISI vigente.

De los indicadores de reponderación por volatilidad se recomienda dar seguimiento a $\mathrm{R} \_2$ _ inversa_volat por varias razones: presenta mejor ajuste a la tendencia, un mejor desempeño en una de las pruebas de propiedades de largo plazo y las ponderaciones utilizadas en su cálculo toman en cuenta el peso de cada artículo en el consumo, pues se incluye las ponderaciones de la canasta IPC.

Los indicadores de reponderación por persistencia con el mejor desempeño en todas las pruebas son los calculados con base en estimaciones del espectro de las series de cambios en precios. De ellos, el que presenta un mejor balance de propiedades es el R_2_espect_tent, basado en espectros estimados mediante ventana tipo tent. Se ubica en una posición similar a los demás indicadores de su tipo en la clasificación por insesgamiento, pero presenta mejor ajuste a la tendencia de inflación. Además, de los 32 indicadores considerados, es el que muestra mayor capacidad de pronóstico de la dirección de cambios en inflación y menor influencia de choques transitorios en su variabilidad de largo plazo.

En cuadro 15 se presenta las principales estadísticas de los indicadores de inflación subyacente escogidos y en los gráficos 13 y 14 se presenta su evolución. Nótese que el promedio de cada indicador propuesto se sitúa dentro del rango de la meta del Banco Central para los años considerados en la estimación, de $5 \% \pm 1 p . p$. 
GRÁFICO 13

INDICADOR DE EXCLUSIÓN POR VOLATILIDAD ELEGIDO (ISI_41), E INFLACIÓN SEGÚN IPC, ISI E IMT Variaciones interanuales

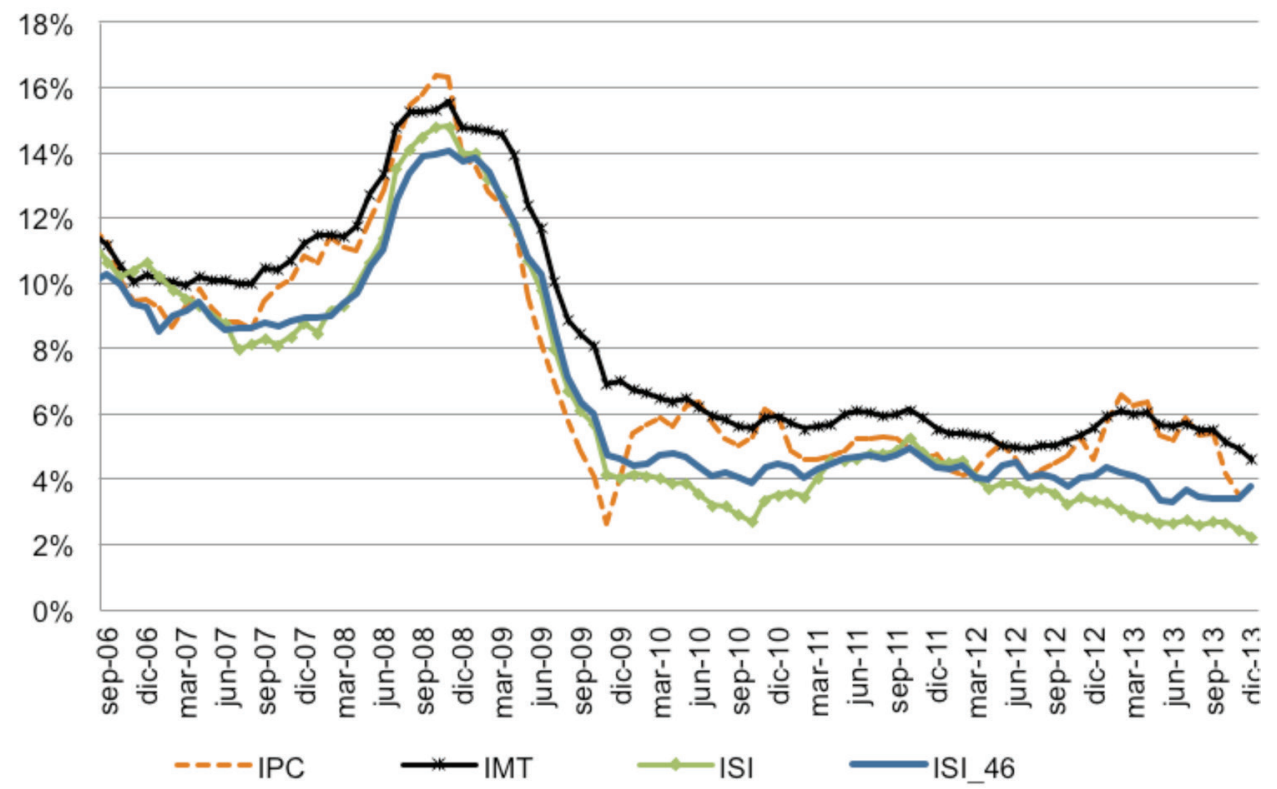

Fuente: elaboración propia.

GRÁFICO 14

INDICADORES DE REPONDERACIÓN POR PERSISTENCIA ELEGIDOS, E INFLACIÓN SEGÚN IPC, ISI E IMT Variaciones interanuales

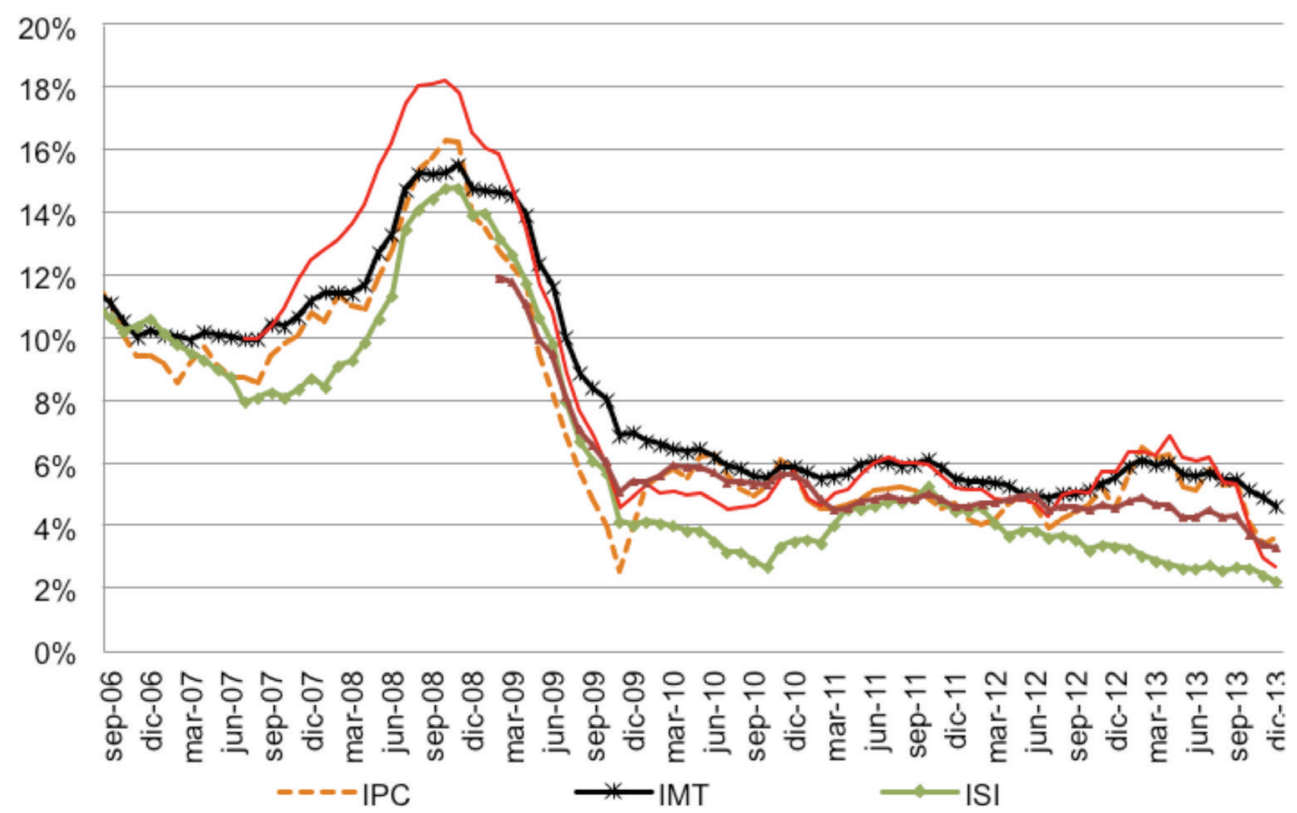

Fuente: elaboración propia. 
CUADRO 15

RESUMEN DE ESTADÍSTICAS PARA INDICADORES DE INFLACIÓN SUBYACENTE E INFLACIÓN IPC MAYO 2009 - DICIEMBRE $2013^{1}$

Puntos porcentuales

\begin{tabular}{cccccr}
\hline & Promedio & Máximo & Mínimo & $\begin{array}{c}\text { Desviación } \\
\text { estándar }\end{array}$ & $\begin{array}{l}\text { Coeficiente } \\
\text { de variación }\end{array}$ \\
\hline IPC & 5,16 & 9,52 & 2,57 & 1,10 & 0,21 \\
ISI & & & & & \\
IMT & 4,09 & 10,67 & 2,22 & 1,61 & 0,39 \\
ISI_46 & 6,18 & 12,40 & 4,63 & 1,49 & 0,24 \\
Reponderación por volatilidad & 4,61 & 10,79 & 3,27 & 1,44 & 0,31 \\
Reponderación por persistencia & 5,21 & 9,99 & 3,33 & 1,19 & 0,23 \\
\hline
\end{tabular}

${ }^{1}$ El período abarca desde el cambio estructural más reciente identificado en el nivel de la inflación. Ver Torres (2012) Fuente: elaboración propia.

\section{CONCLUSIONES Y RECOMENDACIONES}

El estudio de las series revela que no existe un único indicador que consistentemente supere a todos los demás. No obstante, fue posible identificar 4 estimadores que se destacaron por sus resultados generales y complementariedad.

De las medidas de inflación subyacente que publica actualmente el BCCR, el IMT presentó buenos resultados en la mayoría de los criterios evaluados, destacándose su ajuste a la tendencia de la inflación y su capacidad predictiva. Asimismo, el ISI vigente evidenció la propiedad deseable del insesgamiento, pero su desempeño en las pruebas de bondad del ajuste, predicción de cambios y propiedades de largo plazo estuvo por debajo de las demás series, incluso siendo superado por algunos de los nuevos indicadores que se evaluaron en esta investigación.

Entre las 11 medidas de exclusión ISI_j propuestas, se destaca la ISI_46, que resultó insesgada en 4 de los 5 horizontes relevantes de la prueba conjunta, y superó al ISI vigente en bondad de ajuste a la tendencia de inflación y en capacidad predictiva según la especificación de Diebold-Mariano. En consecuencia, se recomienda adoptar al ISI_46 como indicador de inflación subyacente, dado su desempeño superior en las otras pruebas.

Adicionalmente, se concluye que los indicadores con doble ponderación en general presentan mejor desempeño que los de ponderación simple. La inclusión de la información sobre peso en consumo aportada por las ponderaciones originales en la canasta del IPC mejora de forma significativa el desempeño de los indicadores de inflación subyacente calculados mediante reponderación.

Además, dentro del grupo de nuevos indicadores propuestos para Costa Rica, la reponderación por espectro junto con las medidas de inverso de la volatilidad presentaron los mejores resultados para la predicción de la dirección de cambios, incluso superando en algunos criterios a las series ISI $y$ al IMT.

En relación con las propiedades de largo plazo, las medidas basadas en reponderación por espectro y por el inverso de la volatilidad histórica presentan propiedades deseables como indicadores de inflación subyacente para el caso de Costa Rica, presentando incluso mejor desempeño que el ISI vigente, $y$ resultados muy cercanos a los obtenidos por la IMT. 
En conclusión, se recomienda dar seguimiento a un conjunto de indicadores complementarios de inflación subyacente. Se sugiere incluir la IMT, el indicador de exclusión ISI_46 y dos medidas adicionales según los enfoques de reponderación que se utilizaron en esta investigación (por volatilidad y por persistencia). La incorporación de estas dos medidas adicionales se justifica tanto por su adecuado desempeño en las pruebas como por su complementariedad conceptual. De los indicadores reponderados por volatilidad se recomienda utilizar el R_2_inverso_volat, que realiza una doble ponderación por el inverso de la volatilidad histórica de los cambios en precio, y de los reponderados por persistencia se recomienda el indicador R_2_espect_tent, en el que la responderación se basa en una estimación mediante ventana tent del espectro de las series de cambios en precios.

\section{BIBLIOGRAFÍA}

Andrews, D. W., \& Chen, H. (1994). Approximately Median-Unbiased Estimation of Autoregressive Models. Journal Of Business And Economic Statistics, 12(2), 187-204.

Bai, J., \& Perron, P. (2003). Computing and analysis of multiple structural change models. Journal of applied econometrics.18, 1-22.

Batini, N., \& Nelson, E. (2002). The lag from monetary policy actions to inflation: Friedman revisited (Bank of England Discussion Paper No.6).

Bilke, L., \& Stracca, L. (2008). A Persistence-weighted measure of core inflation in the Euro zone. European Central Bank: working paper series No. 905, 1-27.

Blinder, A. (1997). Comentarios sobre artículo de Stephen G. Cecchettis: Measuring Short- Run Inflation for Central Bankers. Review, 157-160.

Capistrán, C., \& Ramos-Francia, M. (2009). Inflation Dynamics in Latin America. Contemporary Economic Policy, 27(3), 349-362.

Chaverri, C., \& Torres, C. (2010). Dinámica inflacionaria y persistencia en Costa Rica: Periodo 19532009 (Documento de Investigación 02-201). Departamento de Investigación Económica, Banco Central de Costa Rica.

Cogley, T. (2002). A Simple Adaptive Measure of Core Inflation. Journal of Money, Credit, and Banking, 34(1).

Cogley, T., \& Sargent, T. (2001). Evolving Post-World War II U.S. Inflation Dynamics. En B. Bernanke, \& K. Rogoff (Edits.), NBER Macroeconomics Annual 2001 (Vol. 16, págs. 331-388). MIT Press.

Cogley, T., \& Sargent, T. (2005). Drift and Volatilities: Monetary Policies and Outcomes in the Post WWII U.S. Review of Economic Dynamics, 8(2), 262-302.

Cutler, J. (2001). Core Inflation in the UK. External MPC Unit Discussion Paper No. 3, 1-29.

D’Amato, L., Garegnani, L., \& Sotes, J. (Enero-marzo de 2008). Dinámica inflacionaria y persistencia: implicancias para la política monetaria. Ensayos económicos, 50, 127-167.

Dias, D., \& Marques, S. R. (2005). Using Mean Reversion as a Measure of Persistence (Working Paper Series No. 450). European Central Bank.

Diebold, F., \& Mariano, R. (1995). Comparing Predictive Accuracy. Journal of Business and Economic Statistics, 13, 253-265.

Diewert, E. W. (1995). On the Stochastic Approach to Index Numbers (Department of Economics Discussion Paper No. 95/31). University of British Columbia.

Edgeworth, F. Y. (1887). Measurement of Change in Value of Money I. En Papers Relating to Political Economy New York (1925) (Vol. 1). New York: Burt Franklin.

Edgeworth, F. Y. (1923). Mr. Correa Walsh on the Calculation of Index-Numbers. Journal of the Royal Statistical Society, $86,570-590$.

Esquivel Monge, M., Rodríguez Vargas, A., \& Vásquez Carvajal, J. P. (2011). Medias truncadas del IPC como indicadores de inflación subyacente en Costa Rica (Documento de Investigación 01-2011). Departamento de Investigación Económica, Banco Central de Costa Rica. 
Gordon, R. J. (1975). Alternative Responses of Policy to External Supply Shocks. Brookings Papers in Economic Activity 6.

Granger, C., \& Hatanaka, M. (1971). Spectral Analysis of Economic Time Series (Princeton Studies in Mathematical Economics). Princeton, NJ, EE.UU: Princeton University Press.

Hamilton, J. (1994). Time Series Analysis. Princeton, NJ, EE.UU: Princeton University Press.

Hogan, S., Johnson, M., \& Laflèche, T. (2001). Core Inflation (Technical Report No. 89). Research Department, Bank of Canada.

INEC. (2006). Metodología del Índice de Precios al Consumidor. San José: Instituto Nacional de Estadística y Censos.

Lahura, E., \& Vega, M. (2011). Wavelet-based Core Inflation Measures (Working Papers 2011-019). Banco Central de Reserva del Perú.

Rodríguez Vargas, A. (2011). Análisis espectral de indicadores de precios en Costa Rica (Documento de Investigación No. 07-2011). Departamento de Investigación Económica, Banco Central de Costa Rica.

Saborío, G., Solano, I., \& Solera, Á. (2002). Medidas de núcleo inflacionario para Costa Rica (Documento de Investigación DIE-DM-DCS/08-2002-DI). Departamento de Investigación Económica, Banco Central de Costa Rica.

Torres, C. (2012). Costa Rica: Determinación de cambios estructurales en el nivel de la tasa de inflación: periodo 1997 - 2011 (Documento de Trabajo 02-2012). Departamento de Investigación Económica, Banco Central de Costa Rica.

Willis, J. (2003). Implications of structural changes in the U.S. economy for pricing behavior and inflation dynamics. (F. R. City, Ed.) Economic Review (primer trimestre). 


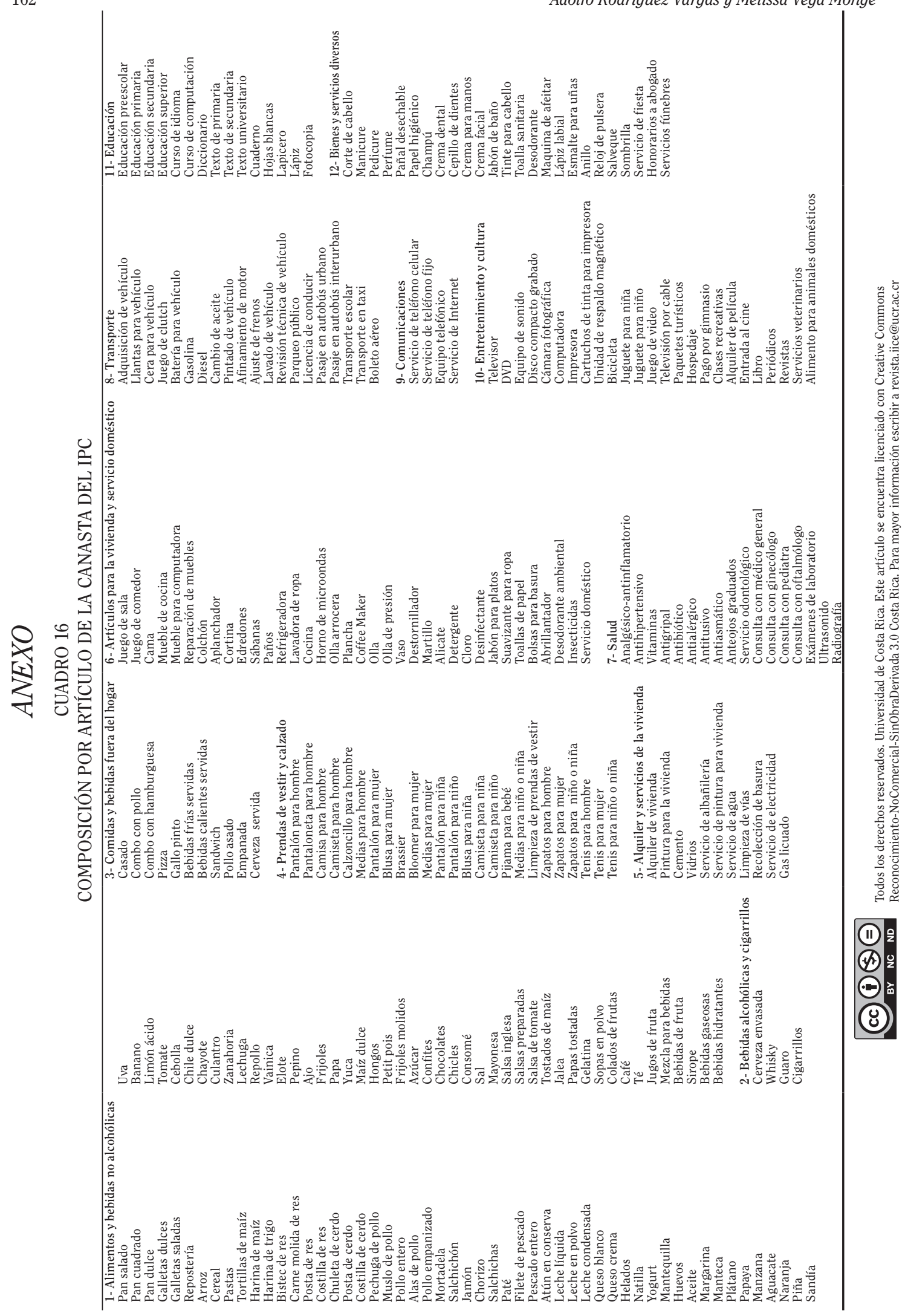

